\title{
$\beta$-环糊精的固载及其应用最新研究进展
}

\author{
沈海民 $*, a$ 纪红兵 ${ }^{b}$ 武宏科 ${ }^{a}$ 史鸿金鍂*a \\ ( ${ }^{a}$ 浙江工业大学化学工程学院 杭州 310014) \\ ${ }^{b}$ 中山大学化学与化学工程学院 广州 510275)
}

\begin{abstract}
摘要 环糊精由于其优异的结构特征和物理化学性质, 已成为构筑各种功能材料的优良结构单元. 本综述以 $\beta$-环糊精 的共价固载为主, 详细综述了目前 $\beta$-环糊精的固载及其应用最新研究进展, 主要包括固载化 $\beta$-环糊精在环境污染物吸 附、药物分子的负载和缓释、分析检测、手性分离、催化、织物整理和表面功能化等领域的应用. 上述各部分, 根据 载体或应用方式的不同, 系统介绍了 $\beta$-环糊精的固载及固载化 $\beta$-环糊精的性能. 指出固载化 $\beta$-环糊精在催化和表面功 能化领域的应用虽然目前还处于起步阶段, 却极具研究价值, 对固载化 $\beta$-环糊精进一步的功能化是今后基于 $\beta$-环糊精 构筑超分子仿生催化体系的主要研究方向.
\end{abstract}

关键词 $\beta$-环糊精; 固载; 应用; 进展

\section{Recent Advances in the Immobilization of $\beta$-Cyclodextrin and Their Application}

\author{
Shen, Haimin ${ }^{*, a}$ \\ Ji, Hongbing ${ }^{b}$ \\ $\mathrm{Wu}$, Hongke ${ }^{a}$ \\ Shi, Hongxin *,a \\ ( ${ }^{a}$ College of Chemical Engineering, Zhejiang University of Technology, Hangzhou 310014) \\ ( ${ }^{b}$ School of Chemistry and Chemical Engineering, Sun Yat-Sen University, Guangzhou 510275)
}

\begin{abstract}
Cyclodextrin has become an excellent unit in the construction of various functional materials due to its unique structural characteristics and physical-chemical properties. Herein, the immobilization of $\beta$-cyclodextrin and their application at present have been reviewed in detail focusing on the covalent immobilization, especially including the application of the immobilized $\beta$-cyclodextrin in the environmental pollutants adsorption, drug loading and releasing, analysis and detection, chiral separation, catalysis, textile finishing, surface functionalization and so on. In the application mentioned above, the immobilization of $\beta$-cyclodextrin and their performance were presented systematically according to the supporter or application modes. It is pointed out that the applications of the immobilized $\beta$-cyclodextrin in catalysis and surface functionalization are just in their infancy, but having promising prospect. The further functionalization of the immobilized $\beta$-cyclodextrin will be the focus in the construction of supramolecular biomimetic catalytic systems based on $\beta$-cyclodextrin in future.
\end{abstract}

Keywords $\beta$-cyclodextrin; immobilization; application; advances

自 1891 年 Villiers 发现环糊精, 环糊精已经历了 120 多年的发展, 作为一组通过淀粉生物降解得到的由 $D-(+)$-吡喃葡萄糖单元通过 $\alpha-1,4$-糖苷键连接而成的环 状低聚糖, 环糊精具有 “内腔疏水, 外壁亲水” 的特殊 结构和性质, 并在外型上呈 “截顶圆雉” 状 ${ }^{[1 \sim 3]}$. 在上述 环状低聚糖中, 三个主要成员分别含有 6 个、7 个和 8 个 $D$ - $(+)$-吡喃葡萄糖单元, 即 $\alpha$-环糊精、 $\beta$-环糊精和 $\gamma$ 环糊精, 其中 $\beta$-环糊精价廉易得, 应用最广. 由于 $\beta$-环
糊精的特殊结构和性质, $\beta$-环糊精可以于水相中模拟酶 的疏水口袋，与一系列有机分子形成包结络合物，广泛

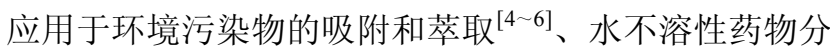
子的包结和增溶 ${ }^{[7 ~ 9]}$ 、水相有机合成反应的促进和催 化 ${ }^{[10 \sim 12]}$ 、超分子仿酶体系的设计与构筑 ${ }^{[13 \sim 17]}$ 等领域. 同 时, $\beta$-环糊精分子结构中富含羟基官能团, 可以借助羟 基的化学反应, 选择性地对 $\beta$-环糊精进行化学修饰, 提 高其性能，拓展其应用领域 ${ }^{[17 ~ 21]}$. 除了以 $\beta$-环糊精为母

\footnotetext{
*E-mail: haimshen@zjut.edu.cn

Received February 19, 2014; revised March 14, 2014; published online April 10, 2014

Project supported by the National Natural Science Foundation of China (No. 21306176) and the Scientific Research Launching Foundation of Zhejiang University of Technology (No. G2817101103).

国家自然科学基金(No. 21306176)和浙江工业大学科研启动基金(No. G2817101103)资助项目.
} 
体进行化学修饰拓展其应用外, $\beta$-环糊精的共价固载也 是其应用拓展的一个重要方向, 固载化不仅可以很好地 保持 $\beta$-环糊精固有的空腔结构及其它优良性质, 避免交 联聚合造成的环糊精空腔结构的剧烈变化甚至破坏, 而 且还可以克服其水溶性好, 回收困难的缺陷, 甚至取得 $\beta$-环糊精单元与载体二者协同作用的良好效果.

目前, $\beta$-环糊精的固载按载体的不同, 可分为在无

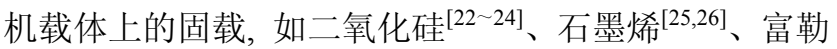
烯 ${ }^{[27]}$ 、量子点 ${ }^{[28]}$ 等; 在有机合成高分子材料上的固载,

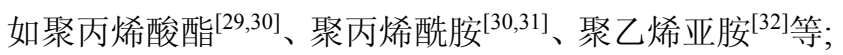

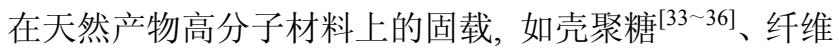
素 ${ }^{[35]}$ 等. 按照固载化 $\beta$-环糊精用途的不同, 可分为环境 污染物的吸附、药物分子的负载和缓释、分析检测、手 性分离、催化、织物整理和表面功能化. 本综述结合作 者本人基于 $\beta$-环糊精设计构筑均相超分子仿生催化剂 的研究 ${ }^{[37 \sim 42]}$, 针对基于 $\beta$-环糊精所构筑的均相超分子 仿生催化剂水溶性好, 回收困难, 催化反应对映选择性 不高等缺陷, 及目前还未见关于 $\beta$-环糊精固载及其应用 的全面详细的综述性文章, 按应用领域的不同, 详细综 述了 $\beta$-环糊精的固载及其应用的最新研究进展. 各应用 领域中, 又按固载载体的不同, 对 $\beta$-环糊精的固载及其 应用进行了分类介绍. 另外, $\mathrm{Fe}_{3} \mathrm{O}_{4}$ 纳米粒子作为 $\beta$-环糊 精固载的优良载体, 已单独进行综述 ${ }^{[43]}$, 在此不再赘 述.

\section{1 环境污染物的吸附}

固载化 $\beta$-环糊精吸附环境污染物, 主要是借助 $\beta$-环 糊精单元对环境污染物分子的包结络合作用, 将环境污 染物包结富集, 同时借助载体的易回收特性, 实现环境 污染物从环境中的脱除. 该类吸附剂中, 有时候载体本 身对环境污染物分子也具有一定的吸附性能, 此时, $\beta$ 环糊精单元除了具有环境污染物的包结络合作用, 还具 有增强载体在水相中分散的作用, 从而促进吸附过程的 进行. 目前, 固载化 $\beta$-环糊精包结吸附环境污染物, 载 体主要包括无机材料, 有机合成高分子材料和天然产物 高分子材料.

\section{1 以无机材料为载体}

$\beta$-环糊精固载在无机材料上, 构筑环境污染物吸附 材料, 无机载体主要包括碳纳米管、碳纳米纤维、 $\mathrm{SiO}_{2}$ 粒子、凹凸棒、沸石等, 借助载体的高比表面积增强 $\beta$ 环糊精单元的分散，提高其包结吸附性能，同时 $\beta$-环糊 精在一定程度上也增强了载体在水相中的分散, 促进吸 附过程的进行. 如 Lukhele 等 ${ }^{[44]}$ 以六亚甲基-1,6-二异氧 酸酯为连接基团, 将 $\beta$-环糊精固载在浸渍有 $\mathrm{Ag}$ 纳米粒 子的碳纳米管上, 构筑水处理材料 Immo-CD-1. 由于
$\mathrm{Ag}$ 纳米粒子和 $\beta$-环糊精单元的同时存在, 该材料不仅 可以有效杀死水相中的细菌, 而且还可以吸附水相中的 环境污染物, 如 $p$-硝基苯酚, $0.03 \mathrm{~g}$ 上述材料可以将 $30 \mathrm{~mL} 10 \mu \mathrm{g} / \mathrm{g} p$-硝基苯酚水溶液中 $58 \%$ 的 $p$-硝基苯酚吸 附, 是一性能优异的水处理材料. Shao 等 ${ }^{[45]}$ 则通过等离 子体技术将 $\beta$-环糊精固载在多层碳纳米管上，构筑吸附 材料 Immo-CD-2, 吸附水相中的多氯联苯, 该吸附材料 兼具 $\beta$-环糊精单元包结络合预浓缩水相中多氯联苯的 功能和多层碳纳米管对多氯联苯的结合吸附性能，具有 很高的吸附容量, 对 4,4'-二氯联苯和 2,3,3'-三氯联苯的 饱和吸附容量分别达到了 261 和 $235 \mathrm{mg} / \mathrm{g}$. 该吸附材料 通过预浓缩一固定化吸附水相中的多氯联苯, 吸附速率 快, 饱和吸附容量大, 具有应用于大规模环境污水处理 的潜力. 除此以外, Bhoi 等 ${ }^{[46]}$ 和 Song 等 ${ }^{[47]}$ 分别通过酰胺 键将 $\beta$-环糊精固载在多层碳纳米管上(Immo-CD-3), 吸 附水相中的染料罗丹明 $6 \mathrm{G}$ 和环境污染物 $\beta$-萗酚, 均取 得了令人满意的结果. 除了碳纳米管, Chen 等 ${ }^{[48]}$ 还以环 氧氯丙烷为连接基团, 将 $\beta$-环糊精固载在碳纳米纤维 上, 制成碳纳米纤维膜, 吸附水相中的品红酸, 饱和吸 附容量达到了 $132.43 \mathrm{mg} / \mathrm{g}$, 明显高于市售颗粒活性炭 的饱和吸附容量, $34.20 \mathrm{mg} / \mathrm{g}$. 该固载了 $\beta$-环糊精单元的 碳纳米纤维膜，不仅可广泛应用于分子过滤和有机污染 物的吸附, 通过对碳纳米纤维膜进行进一步的功能化, 其还具有广泛应用于手性分离和药物输送等领域的潜 力.
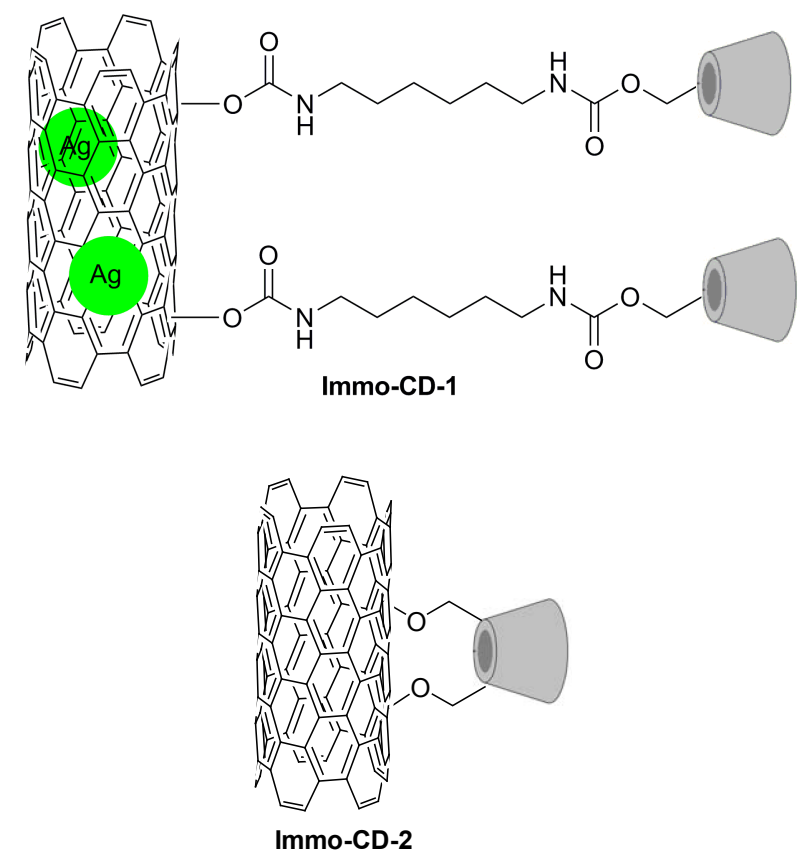

$\mathrm{SiO}_{2}$ 粒子也是 $\beta$-环糊精固载的常用无机载体, Roik 等 ${ }^{[49]}$ 以(3-氨基丙基)三甲氧基硅烷为连接基团, 借助羰 基二咪唑的活化作用，将 $\beta$-环糊精固载在 $\mathrm{SiO}_{2}$ 粒子上, 


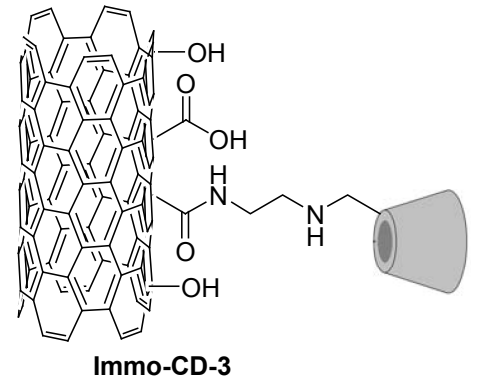

构筑吸附材料 Immo-CD-4 吸附水相中的 $p$-氨基苯甲酸 和 $p$-氨基水杨酸, 平衡吸附量分别达到了 21.91 和 4.52 $\mu \mathrm{mol} / \mathrm{g}$. Chen 等 ${ }^{[50]}$ 也报道了以(3-氨基丙基)三甲氧基硅 烷为连接基团, 将 $\beta$-环糊精固载在纳米 $\mathrm{SiO}_{2}$ 上 (Immo-CD-5), 吸附染料废水中的染料分子, 以偶氮染 料刚果红为例, 该吸附材料吸附的偶氮染料可以方便地 在 $\beta$-环糊精或垟丙基 $\beta$-环糊精作为脱附剂的情况下脱 附，起到富集刚果红的作用，将刚果红的浓度提高了 30 倍, 进而将富集的污染物分子电化学降解, 提供了一种 富集大体积废水中有机污染物并将其降解的有效方法.

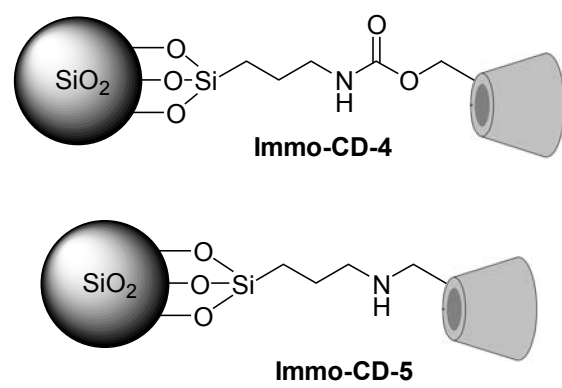

另外, Fuhrer 等 ${ }^{\left[{ }^{151}\right.}$ 以 1,6-六亚甲基二异氰酸酯为连 接基团, 将 $\beta$-环糊精固载在碳包覆的磁性钴纳米粒子 上, 构筑吸附材料 Immo-CD-6, 吸附水相中的环境污染 物. 以酚酞为模型化合物, 该吸附剂不仅可以迅速吸附 水相中的酚酞, 并且脱附容易, 重复使用 16 次未见吸附 性能的明显下降, 是一性能优异的水相环境污染物吸附 材料. Pan 等 ${ }^{[52]}$ 则报道了以(3-缩水甘油氧基丙基)三甲氧 基硅烷为连接基团, 将 $\beta$-环糊精固载在 $\mathrm{Mg}$-Al-Si 凹凸 棒上, 作为吸附材料 Immo-CD-7, 吸附水相中的 2,4-二 氯苯酚和 2,6-二氯苯酚, $25{ }^{\circ} \mathrm{C}$ 下饱和吸附量分别达到了 41.49 和 $29.33 \mathrm{mg} / \mathrm{g}$, 并表现出一定的选择性吸附. 除了 共价固载, $\mathrm{Li}$ 等 ${ }^{[53]}$ 还借助季铵盐 $\mathrm{N}$ 正离子与沸石表面富 集的负电荷的静电相互作用, 将 $\beta$-环糊精固载在沸石 上, 作为吸附材料 Immo-CD-8, 吸附水相中的硝基苯 酚, 饱和吸附量最高达到 $256.48 \mu \mathrm{g} / \mathrm{g}$. Shen 等 ${ }^{[54]}$ 通过水 热法将 $\beta$-环糊精和 $\mathrm{TiO}_{2}$ 非共价固载在化学还原的氧化 石墨烯上, 构筑超分子光催化和吸附材料, 吸附降解水 相中的环境污染物苯酚并吸附环境中的重金属离子
$\mathrm{Cr}(\mathrm{VI})$. 该材料兼具 $\beta$-环糊精的吸附和分子识别性能、 石墨烯的优异电化学性能和高比表面积与 $\mathrm{TiO}_{2}$ 的光催 化性能, $120 \mathrm{~min}$ 就可将水相中的苯酚几乎全部光催化 吸附降解，重金属离子 $\mathrm{Cr}(\mathrm{VI})$ 也几乎全部吸附，是一性 能优异的光催化材料和吸附材料.
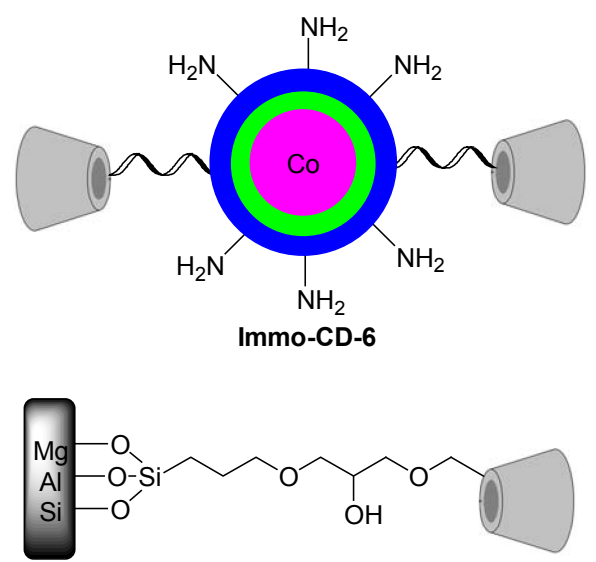

Immo-CD-7

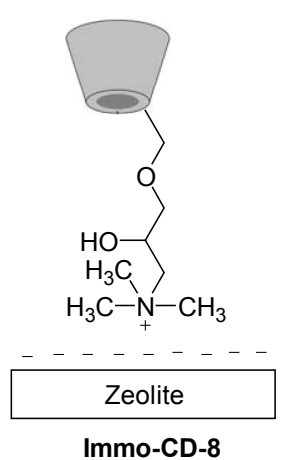

\section{2 以有机合成高分子材料为载体}

$\beta$-环糊精固载在有机合成高分子材料上，构筑环境 污染物吸附材料, 有机合成高分子载体主要包括聚丙烯 酸类高分子材料、聚丙烯、聚乙烯醇、聚乙烯亚胺等，固 载的实现主要是通过以含有 $\beta$-环糊精单元的单体与其 它共聚单体共聚或高分子材料表面的接枝技术. 如 Jiang 等 ${ }^{[5]}$ 以甲基丙烯酸(三甲基氨基)乙基酯氯化物与 $\beta$-环糊精马来酸酯为共聚单体聚合合成了两亲絮凝剂 Immo-CD-9, 实现了 $\beta$-环糊精的固载. 以该固载化 $\beta$-环 糊精吸附絮凝水相中的染料分子，以酸性嫩黄 $2 \mathrm{G}$ 为例, 在絮凝剂与染料分子的质量比为 $1: 10, \mathrm{pH}$ 为 2 时, 可 取得最佳的絮凝脱色效果. 该絮凝脱色过程, 除了 $\beta$-环 糊精单元对染料分子的包结络合外，染料分子与絮凝剂 的静电相互作用也是吸附脱色的主导作用力. Zou 等 ${ }^{[56]}$ 则以具有烯丙基的 $\beta$-环糊精、丙烯酰胺和丙烯酸钠为共 聚单体, 共聚合成了具有 $\beta$-环糊精单元的聚合物 Immo-CD-10, 在聚合物/表面活性剂驱油模拟实验中, 由于 $\beta$-环糊精单元的包结络合作用，该聚合物可以有效 
减少 $20 \%$ 的表面活性剂损失.
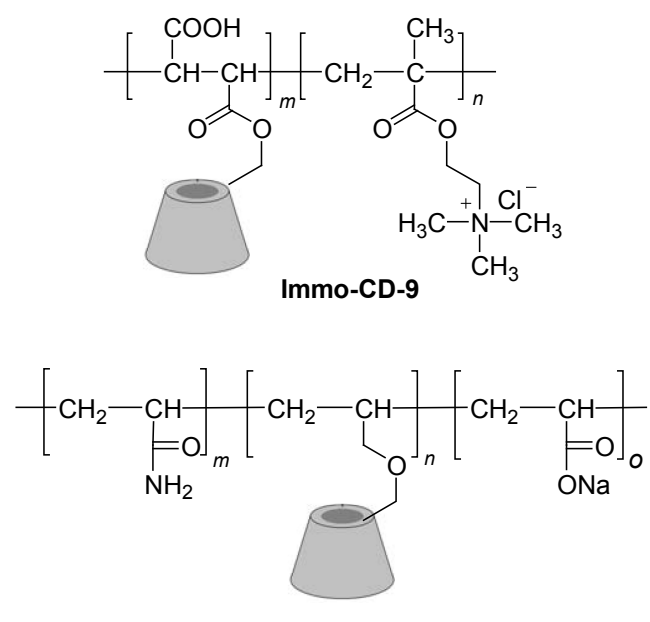

Immo-CD-10

除了直接聚合, Guo 等 ${ }^{[57]}$ 则通过微乳液蒸发技术将 $\beta$-环糊精接枝固载在聚丙烯酸上, 构筑环境污染物吸附 材料 Immo-CD-11, 以 $p$-硝基苯酚为例, 最高吸附容量 达到了 $2.20 \mathrm{mmol} / \mathrm{g}$, 具有用作环境污染物治理吸附材 料和药物负载载体的潜力. Schofield 等 ${ }^{[58]}$ 通过脉冲等离 子体沉积法将 4-乙烯基芐氯沉积在多孔聚丙烯纤维上, 然后借助芐基氯与 $\beta$-环糊精的 Williamson 醚化反应, 将 $\beta$-环糊精接枝固载在多孔聚丙烯纤维上, 形成分层多孔 结构的吸附材料 Immo-CD-12, 吸附工业废水和农业废 水中的有机污染物. 以 2-氯苯酚、2,4,6-三氯苯酚、1,4二氯苯等为例，饱和吸附量分别达到 $0.48 ， 0.46,0.60$ $\mathrm{mmol} / \mathrm{g}$, 并且吸附的有机污染物可以通过调节介质 $\mathrm{pH}$ 值来脱附, 重复使用 3 次而未见吸附性能的明显下降, 是一种吸附环境中有害的含氯苯酚及氯苯类污染物的 优良吸附材料. 另外, Teng 等 ${ }^{[59]}$ 以(3-氨基丙基)三乙氧 基硅烷和三氯均三嗪为连接基团, 将 $\beta$-环糊精固载在聚 乙烯醇 $/ \mathrm{SiO}_{2}$ 静电纺丝纳米纤维膜 $\left(\mathrm{PVA} / \mathrm{SiO}_{2}\right)$ 上, 吸附 水相中的靛蓝胭脂红染料, 饱和吸附容量达到了 495 $\mathrm{mg} / \mathrm{g}$. Yamada 等 ${ }^{[60]}$ 将 $\beta$-环糊精固载在支化聚乙烯亚胺 上(Immo-CD-13), 然后借助静电相互作用将该固载化 $\beta$-环糊精与 DNA 形成复合材料, 作为吸附材料吸附水 相中的环境污染物. 由于该材料兼具 $\beta$-环糊精单元对非 极性有机分子的识别性包结络合作用和 DNA 对极性有 机分子的选择性吸附络合作用, 该复合材料不仅可以成

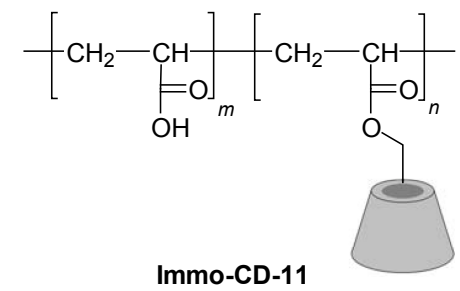

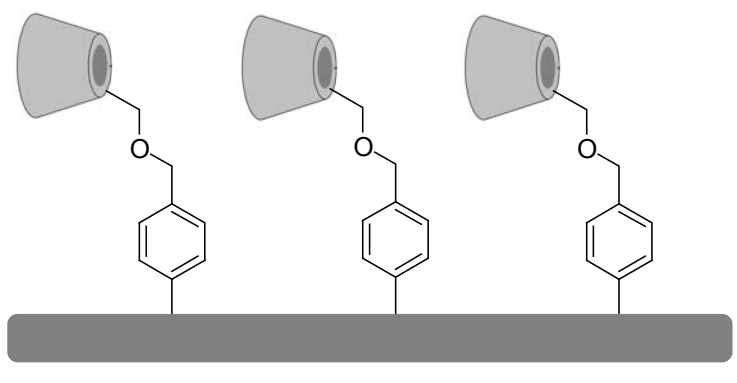

Immo-CD-12

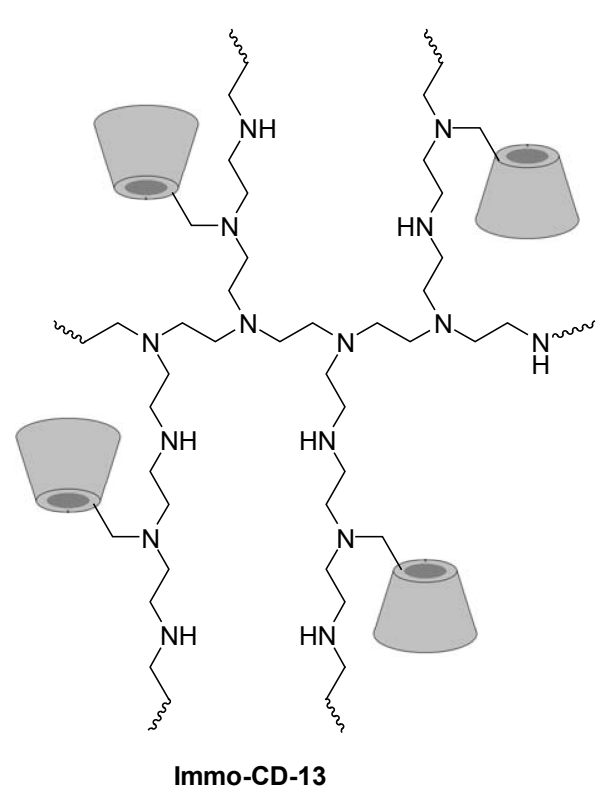

功用于富集环境中二噁英衍生物和多氯联苯衍生物等 极性结构的环境污染物, 而且还可以富集双酚 $\mathrm{A}$ 和已烯 雌酚等非极性分子, 并且可以选择性地从多组分溶液中 富集上述组分. 该复合材料在环境治理、生物医药和功 能材料等领域具有极大的应用潜力.

除了共价固载, Uyar 等 ${ }^{[61]}$ 通过静电纺丝技术将 $\beta$-环 糊精非共价固载在聚甲基丙烯酸甲酯纳米纤维上，由于 部分 $\beta$-环糊精位于纳米纤维的表面上, 可以通过包结络 合作用吸附环境中的有机废气, 如苯胺、苯乙烯和甲苯. 因此，该固载了 $\beta$-环糊精单元的聚甲基丙烯酸甲酯纳米 纤维和纳米纤维膜具有用作分子过滤器或纳米过滤器 处理有机废气和过滤空气的潜力. Lopez-de-Dicastillo 等 ${ }^{[2]}$ 还通过平坦挤压法和压缩成型法将 $\beta$-环糊精非共 价固载在乙烯和乙烯醇的共聚物上，用于食品包装，包 结吸附食品中的非极性化合物, 如萜烯、己醛和胆固醇, 也取得了令人满意的结果.

\section{3 以天然产物高分子材料为载体}

$\beta$-环糊精固载在天然产物高分子材料上，构筑环境 污染物吸附材料, 天然产物高分子载体主要包括壳聚 糖、纤维素、木粉等，固载的实现主要是通过天然产物 
高分子材料表面的接枝技术. 该类固载化 $\beta$-环糊精不仅 具有良好的分散性, 而且由于 $\beta$-环糊精单元与载体部分 均为天然产物, 该类固载化 $\beta$-环糊精还具有良好的生物 兼容性和可降解性, 使用过程中残留在环境中的部分可 生物降解, 环境影响小, 是一绿色环保的环境污染物吸 附材料. 如 Sharma 等 ${ }^{[63]}$ 通过微波诱导将 $\beta$-环糊精固载 在壳聚糖上, 构筑吸附材料 Immo-CD-14, 吸附水相中 的 $\mathrm{Pb}(\mathrm{II})$, 饱和吸附容量达到了 $434.78 \mathrm{mg} / \mathrm{g}$, 并且吸附 的 $\mathrm{Pb}(\mathrm{II})$ 可以在酸性条件下脱附, 重复使用 7 次仍能保 持原有吸附能力的 $37.46 \%$, 是一吸附环境废水中重金 属离子的良好吸附材料. Chai 等 ${ }^{[64]}$ 则以戊二醛为连接基 团, 将 $\beta$-环糊精固载在壳聚糖上, 吸附水相中的苯甲酸, 饱和吸附容量达到 $157.68 \mathrm{mg} / \mathrm{g}$, 显著高于文献报道的 其它的吸附材料的吸附能力. 另外, 该吸附材料的吸附 能力受到吸附体系 $\mathrm{pH}$ 值的影响, 最优 $\mathrm{pH}$ 为 3.68 . 吸附 机理研究发现, 该吸附过程不仅包括 $\beta$-环糊精单元对苯 甲酸的包结络合作用, 还包括壳聚糖主链中氨基与苯甲 酸的静电相互作用. 该吸附材料吸附的苯甲酸脱附容 易, 因此该材料不仅可以用于污水处理, 还可以用于苯 甲酸的回收.

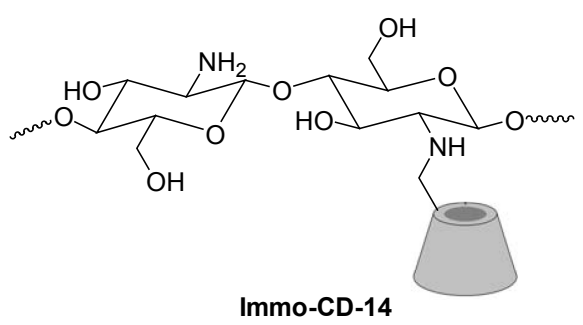

除了以壳聚糖为载体, Zhou 等 ${ }^{\left[{ }^{[5]}\right.}$ 以甲基丙烯酸缩 水甘油酯为连接基团, 将具有季铵盐官能团的 $\beta$-环糊精 衍生物固载在纤维素上, 构筑吸附材料 Immo-CD-15, 吸附水相中的 $\mathrm{Cr}(\mathrm{VI})$, 最高吸附容量达到了 $61.05 \mathrm{mg} / \mathrm{g}$, 并且吸附的 $\mathrm{Cr}(\mathrm{VI})$ 在 $0.5 \mathrm{mg} / \mathrm{L}$ 的 $\mathrm{NaOH}$ 水溶液中可以方 便地脱附, 重复使用 5 次而未见吸附性能的明显下降, 并且由于 $\beta$-环糊精单元的疏水空腔结构, 本吸附剂不仅 可以用于吸附环境污染中的其它重金属离子, 还可以用 于吸附环境污染中的有机化合物, 用途广泛. $\mathrm{Si}$ 等 ${ }^{[66]}$ 以 柠檬酸为连接基团, 将 $\beta$-环糊精固载在木粉共聚物上, 吸附水相中的环境污染物亚甲基绿. 由于 $\beta$-环糊精单元 的引入, 显著提高了该吸附材料对水相中亚甲基绿的吸 附性能, 与木粉共聚物和柠檬酸修饰的木粉共聚物相 比, $\beta$-环糊精单元引入后分别将亚甲基绿的饱和吸附容 量由 33.33 和 $61.73 \mathrm{mg} / \mathrm{g}$ 提高到了 $86.21 \mathrm{mg} / \mathrm{g}$.

除了 $\beta$-环糊精的固载, Mishra 等 ${ }^{[67]}$ 还将 $\gamma$-环糊精固 载在壳聚糖上, 构筑吸附材料, 吸附水相中的重金属离 子 $\mathrm{Cd}(\mathrm{II})$, 饱和吸附容量最高达到了 $833.33 \mathrm{mg} / \mathrm{g}$, 并且

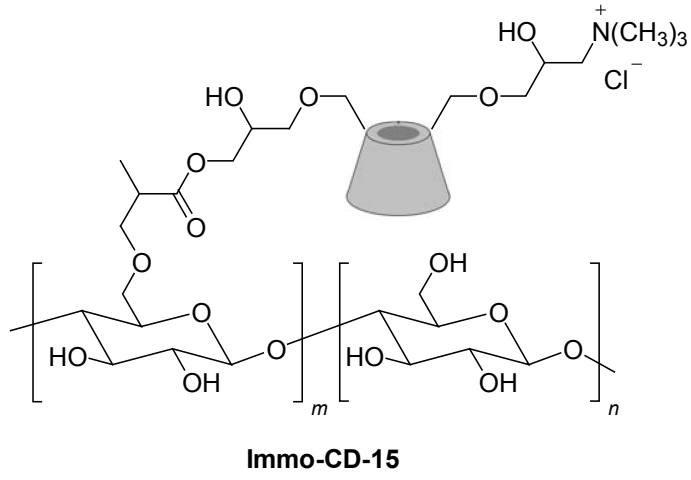

吸附的 $\mathrm{Cd}(\mathrm{II})$ 在 $0.01 \mathrm{~mol} / \mathrm{L}$ 的 $\mathrm{H}_{2} \mathrm{SO}_{4}$ 水溶液中很容易脱 附, 重复使用 9 次, 仍能保持吸附材料 $27 \%$ 的吸附能力.

$\beta$-环糊精固载构筑吸附材料, 除了上述吸附环境污 染物外, 在其它吸附领域也有涉足, 如 Qiao 等 ${ }^{[68]}$ 以组氨 酸为连接基团, 将 $\beta$-环糊精固载在琼脂凝胶上, 构筑中 间分子肽 DFLAE (DE5)的特殊亲和性吸附剂 ImmoCD-16. 由于该吸附剂兼具 $\beta$-环糊精单元的包结络合位 点和组氨酸的静电作用位点, 与寡肽 DFLAE (DE5)表 现出很好的特殊亲和性. 随后作者还根据计算机分子模 拟的结果，设计出对寡肽 DFLAE (DE5)和含有寡肽 DFLAE (DE5)片段的寡肽均具有特殊亲和性能的固载 化 $\beta$-环糊精 Immo-CD-17. 该研究不仅提供了一种吸附 去除中间分子肽的吸附剂, 而且还提供了一种设计特殊 亲和性吸附剂的策略. Tahir 等 ${ }^{[69,70]}$ 则报道了将 $\beta$-环糊精 固载在玻璃表面上, 用于吸附降低牛奶中的胆固醇, 25 ${ }^{\circ} \mathrm{C}$ 振荡 $4.0 \mathrm{~h}$, 可将牛奶中 $73.6 \%$ 的胆固醇吸附, 是迄今 为止将 $\beta$-环糊精固载在固体表面降低牛奶中胆固醇含 量取得的最佳值. 另外, 本吸附体系所固载的 $\beta$-环糊精 稳定性及牢度好, 重复使用 10 次, 仍可将牛奶中 (72士 $2) \%$ 的胆固醇吸附，固载牢固度和重复使用性好，具有 应用于工业规模连续化降低牛奶中胆固醇含量的潜力.
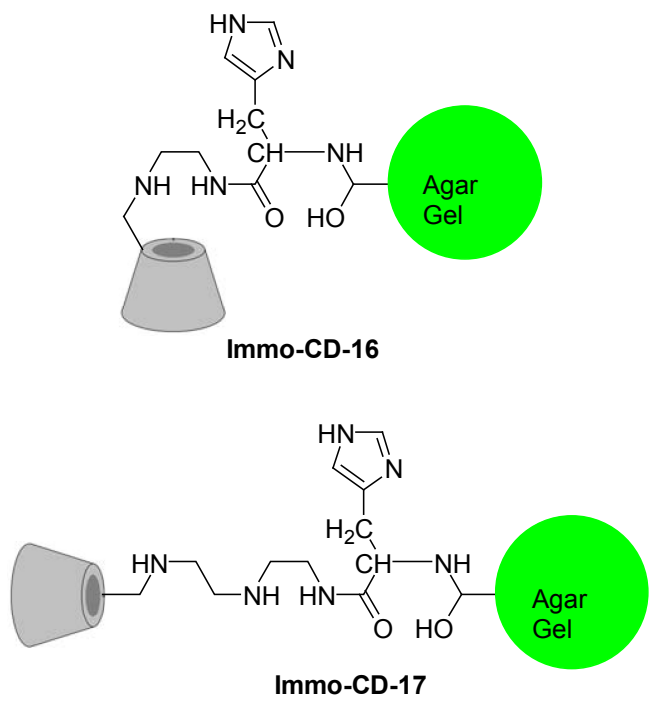
由此可见, 将 $\beta$-环糊精固载构筑吸附材料, 不仅很 好地保持了 $\beta$-环糊精单元固有的包结络合性能, 并提高 其分离及重复使用性能, 而且 $\beta$-环糊精单元与载体之间 的相互作用往往可以显著强化二者对环境污染物等吸 附质的吸附性能, 取得同时优于 $\beta$-环糊精母体和载体的 协同作用效果. 因此, 基于 $\beta$-环糊精的固载构筑吸附材 料仍将是今后吸附材料构筑的重要手段, 尤其是将 $\beta$-环 糊精固载在高分散性的天然产物高分子上, 如壳聚糖、 纤维素、木质素等, 该类吸附材料充分发挥其环境治理 性能后, 最终可生物降解, 不会造成附加的环境污染问 题, 并且来源相对可再生, 前景良好.

\section{2 药物分子的负载、输送和缓释}

固载 $\beta$-环糊精构筑药物分子负载、输送和缓释载体, 所用载体同样主要包括无机材料、有机合成高分子材料 和天然产物高分子材料, 在该药物分子负载、输送和缓 释体系中, 载体本身往往具有一定的药物分子负载、输 送和缓释性能, $\beta$-环糊精单元的引入不仅可以通过包结 络合作用提升药物分子的负载量, 并起到缓释的作用, 而且 $\beta$-环糊精单元的引入还可以显著降低该药物分子 负载、输送和缓释体系的细胞毒性, 提高其生物兼容性. 另外, 由于载体的存在, 本体系在负载、输送和缓释药 物分子的同时, 还可以负载 DNA 或 siRNA, 甚至靶向 输送配体, 因此, 可以将多种具有疗效的药物分子同 时、靶向输送的病变部位, 并控制性缓慢释放, 起到协 同治疗、高效治疗的效果.

\section{1 以无机材料为载体}

$\beta$-环糊精固载在无机材料上, 构筑药物分子负载、 输送和缓释体系, 无机载体主要包括石墨烯、蒙脱石、 $\mathrm{SiO}_{2}$ 粒子、磷酸盐陶瓷等, $\beta$-环糊精单元的引入使上述 无机载体的药物分子负载能力和缓释效果有了明显的 提高, 并且生物兼容性也得到了提高. 如 Wei 等 ${ }^{[71]}$ 以 $\mathrm{p}$ 氨基苯甲酸和聚乙烯亚胺为连接基团, 将 $\beta$-环糊精固载 在石墨烯上, 构筑药物负载和输送体系, 负载输送抗癌 药物阿霉素. $\beta$-环糊精单元的引入, 不仅降低了该药物 输送体系的细胞毒性, 提高其生物兼容性, 而且也使药 物分子的负载量有所提高, 阿霉素的负载量最高达到了 $24.64 \%$. 该药物负载和输送体系, $\beta$-环糊精单元和石墨 烯部分, 均起到了药物分子的负载作用, 并且药物分子 的释放受到体系 $\mathrm{pH}$ 和盐浓度的影响, 可控制性释放药 物分子. Anirudhan 等 ${ }^{[72]}$ 以马来酸酐和(3-三甲氧基硅烷 基丙醇)甲基丙烯酸酯为连接基团, 将 $\beta$-环糊精固载在 钠基蒙脱石上, 作为四环素盐酸盐的结肠给药载体 Immo-CD-18. 该给药载体兼具钠基蒙脱石的控制释放 性能和 $\beta$-环糊精的主一客体包结络合作用, 成功将四环
素盐酸盐输送到结肠，并且没有损失，是一很好的口服 药物输送载体. Hbaieb 等 ${ }^{[73]}$ 以(3-氨基丙基)甲基二甲氧 基硅烷为连接基团, 将 $\beta$-环糊精固载在纳米 $\mathrm{SiO}_{2}$ 粒子 上, 构筑药物负载和缓释载体 Immo-CD-19. 以抗菌药 物灰黄霉素为例，由于 $\beta$-环糊精单元的包结络合作用， 该药物负载载体对灰黄霉素的负载量达到了 $55 \mu \mathrm{mol} / \mathrm{g}$, 显著高于 $\mathrm{SiO}_{2}$ 粒子和(3-氨基丙基)甲基二甲氧基硅烷修 饰的 $\mathrm{SiO}_{2}$ 粒子的负载能力, 2.35 和 $3.15 \mu \mathrm{mol} / \mathrm{g}$. 另外, 该药物负载载体负载抗菌药物灰黄需素, 还可以减少药 物向皮肤深处的渗透，避免药物分子进入体液循环系 统, 副作用低. 另外, Jacobsen 等 ${ }^{[74]}$ 则以(3-缩水甘油氧 基丙基)三甲氧基硅烷为连接基团, 将 $\beta$-环糊精固载在 磷酸盐陶瓷上(Immo-CD-20), Tang 等 ${ }^{[75]}$ 以 3-(2,3-环氧 丙氧基)丙基三甲氧基硅烷为连接基团, 将 $\beta$-环糊精共 价固载在羟基磷灰石复合材料上，作为药物分子的负载 载体和控制释放载体，均取得了很好的效果.
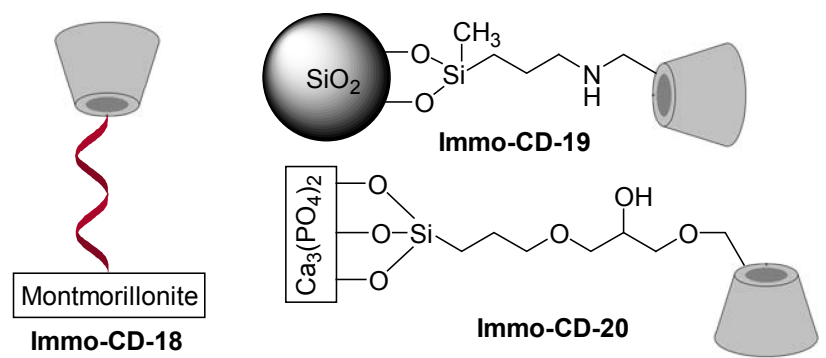

除了共价固载, Zhao 等 ${ }^{[76]}$ 以氨基酸 $(L-$ 组氨酸、 $L$ 色氨酸、 $L$-苯丙氨酸和 $L$-半胱氨酸)为连接基团, 将 $\beta$ 环糊精固载在 $\mathrm{CdSe} / \mathrm{ZnSe}$ 核-壳结构的纳米量子点上, 构筑 siRNA 负载和输送载体 Immo-CD-21. $\beta$-环糊精的 负载，显著提高了量子点的生物兼容性，降低了其细胞 毒性，成功将 siRNA 输送到细胞质的囊泡中，并且基因 沉默效率也有所提高. 结合纳米量子点的光学性质, 本 研究不仅提供了一种 siRNA 负载和输送载体, 还提供了 一种跟踪和监测 siRNA 输送的方法. Shi 等 ${ }^{[77]}$ 则通过非 共价相互作用将全(6-脱氧-6-颈基)- $\beta$-环糊精固载在金 纳米粒子上，通过金刚烷基与 $\beta$-环糊精单元的主一客体 相互作用，构筑抗癌药物顺铂输送体系. 研究发现，该 金纳米粒子上的 $\beta$-环糊精覆盖密度达到了 $210 \beta$-环糊精 /金纳米粒子, 并且其中 150 个 $\beta$-环糊精单元起到了药物 输送功能, 药物负载量相当可观.

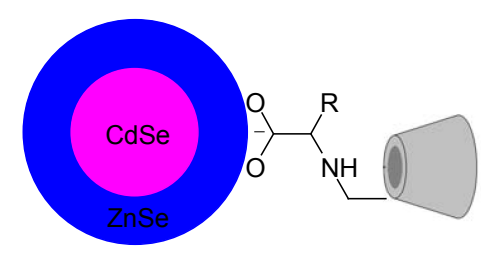

Immo-CD-21 


\section{2 以有机合成高分子材料为载体}

$\beta$-环糊精固载在有机合成高分子材料上，构筑药物 分子负载、输送和缓释材料, 有机合成高分子载体主要 包括含双键单体聚合形成的有机合成高分子、树枝状多 胺类化合物、超支化聚甘油等, 固载的实现主要也是通 过以含有 $\beta$-环糊精单元的单体与其它共聚单体共聚或 高分子材料表面的接枝技术. 该类固载化 $\beta$-环糊精中, 载体的药物分子、siRNA 负载和输送功能相对比较明显, 尤其是树枝状多胺类载体. Trellenkamp 等 ${ }^{[78]}$ 以 $N$-乙烯 基吡咯烷酮及其含有 $\beta$-环糊精单元的衍生物为共聚单 体在 DMF 中自由基共聚, 实现了 $\beta$-环糊精单元在聚 $N$ 乙烯基吡咯烷酮上的固载(Immo-CD-22), 并保持了 $\beta$ 环糊精单元作为主体分子的包结络合性能. 该固载化 $\beta$ 环糊精兼具聚 $N$-乙烯基吡咯烷酮对一些药物分子的结 合性能与 $\beta$-环糊精单元的主体包结络合性能, 可广泛用 作药物分子, 催化剂等的超分子负载和输送载体. Chen 等 ${ }^{[79]}$ 通过 Michael 加成反应将 $N, N^{\prime}$-亚甲基双丙烯酰胺、 1-(2-氨基乙基)哌嗪和单(6-脱氧-6-乙二胺基)- $\beta$-环糊精 共聚, 实现了 $\beta$-环糊精在超支化聚酰胺基胺上的固载 (Immo-CD-23). 该接枝 $\beta$-环糊精单元的超支化聚酰胺 基胺, 与未接枝 $\beta$-环糊精单元的超支化聚酰胺基胺相 比, 不仅细胞毒性有了显著的降低, 而且苂光强度显著 增强, 使该接枝 $\beta$-环糊精单元的超支化聚酰胺基胺不仅 可以作为基因负载和输送的载体, 而且可以跟踪监测基 因的输送. 另外, 该超支化聚酰胺基胺接枝的 $\beta$-环糊精 单元还可以包结负载化学药物分子, 使该接枝了 $\beta$-环糊 精单元的超支化聚酰胺基胺可同时作为基因治疗和化 疗的药物输送载体, 在基因治疗和化疗的协同治疗领域 具有极大的应用潜力. Sun 等 ${ }^{[80]}$ 通过共聚将 $\beta$-环糊精固 载在聚天冬氨酸上, 作为消炎药布洛芬的负载载体 Immo-CD-24, 由于 $\beta$-环糊精单元的包结络合作用, 该 载体将布洛芬的负载量由 $1.98 \mathrm{mg} / \mathrm{g}$ 提高到 $4.12 \mathrm{mg} / \mathrm{g}$, 显著增加了布洛芬的负载量. 并且由于该载体水溶性 好, 将布洛芬的水溶性由 $40 \mathrm{mg} / \mathrm{L}$ 提高到 $172.84 \mathrm{mg} / \mathrm{L}$. 同时由于该载体生物兼容性好，可广泛应用于其它疏水 性药物的负载和增溶. 另外, Yhaya 等 ${ }^{[81]}$ 通过 “Click” 反应, 将 $\beta$-环糊精固载在丙烯酰胺和丙烯酸酯的嵌段聚 合物上, 构筑疏水药物分子负载载体, 也取得了令人满 意的结果.

树枝状多胺类化合物是 $\beta$-环糊精固载构筑药物分 子负载、输送和缓释材料的重要载体, 并且载体本身就 具有良好的药物分子、siRNA 负载和输送性能, 甚至苂 光性能. 如 Bohm 等 ${ }^{[82}$ 将 $\beta$-环糊精接枝固载在超支化聚 乙烯亚胺上(Immo-CD-25), 以葱醌类染料 5,8-二氯-1,4二羟基葱醌和 1,4-双- $N$-金刚烷基氨基蒽醌为药物分子

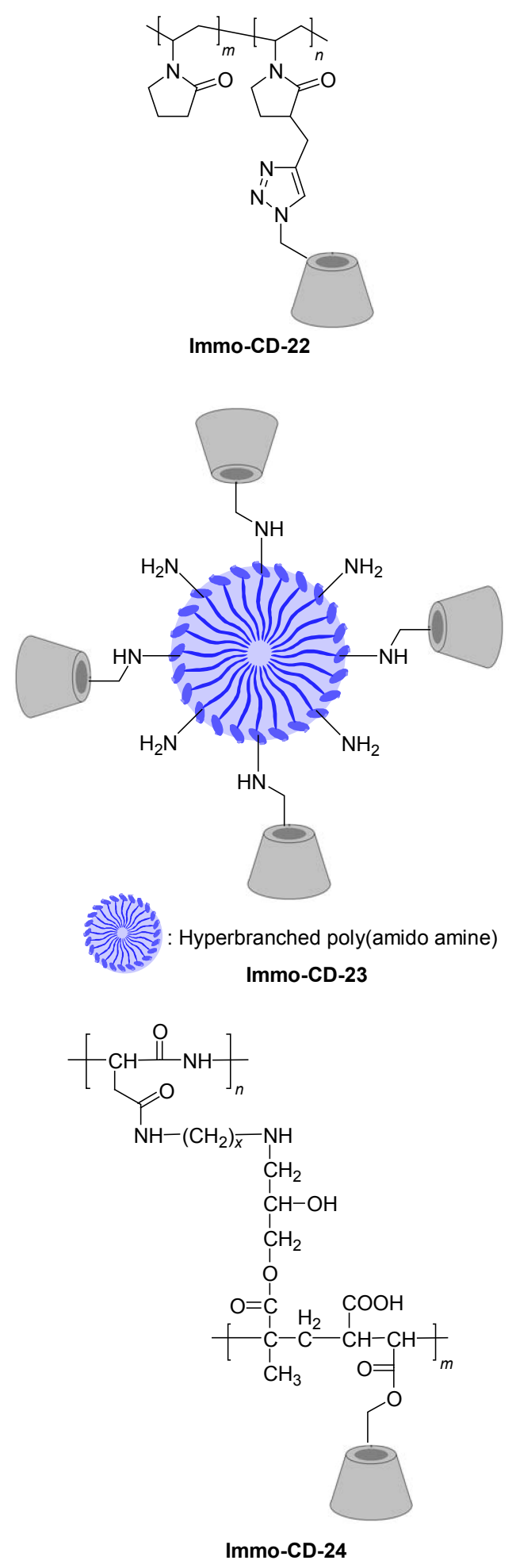

模型, 考察了该固载化 $\beta$-环糊精的药物分子负载性能. 5,8-二氯-1,4-二羟基蒽醌可以通过离子间的静电相互作 用固载在超支化的聚乙烯亚胺上, 并可以通过控制 $\mathrm{pH}$ 控制药物分子的释放; 1,4-双- $N$-金刚烷基氨基蒽醌可以 通过与 $\beta$-环糊精单元形成主-客体包结络合物实现固载, 并可以通过控制温度控制药物分子的释放. 由此可见， 该 $\beta$-环糊精-超支化聚乙烯亚胺药物分子负载载体, 可 
以同时负载两类不同的药物分子, 并在外部刺激下同时 或分别释放所负载的药物分子, 是一种有效的药物分子 负载和控制释放载体. Kim 等 ${ }^{[83,84]}$ 将 $\beta$-环糊精固载在树 枝状多胺上, 构筑 siRNA 和小分子药物输送载体 ImmoCD-26 (Eq. 1), 由于该载体兼具 $\beta$-环糊精单元的疏水药 物分子包结输送性能和树枝状多胺的 siRNA 负载性能, 可同时将抗癌药物和 siRNA 输送到脑癌细胞中, 进行多 组分协同治疗. 另外, 该载体还可以通过进一步的修饰, 将其它药物输送组分负载在该载体上, 如靶向输送配 体, 从而实现将多种癌症治疗试剂一次性靶向输送到病 变细胞, 起到协同治疗的效果. 另外, Yang 等 ${ }^{[85]}$ 将 $\beta$-环 糊精固载在聚乙烯亚胺水凝胶上, 构筑葡萄糖敏感型药 物释放载体, 集中将胰岛素释放在葡萄糖浓度较高的病

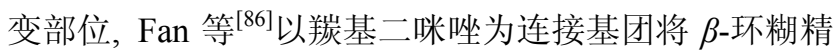
固载在聚乙烯亚胺上, 构筑抗癌药物阿霉素的负载和缓 释载体，均取得了很好的效果.
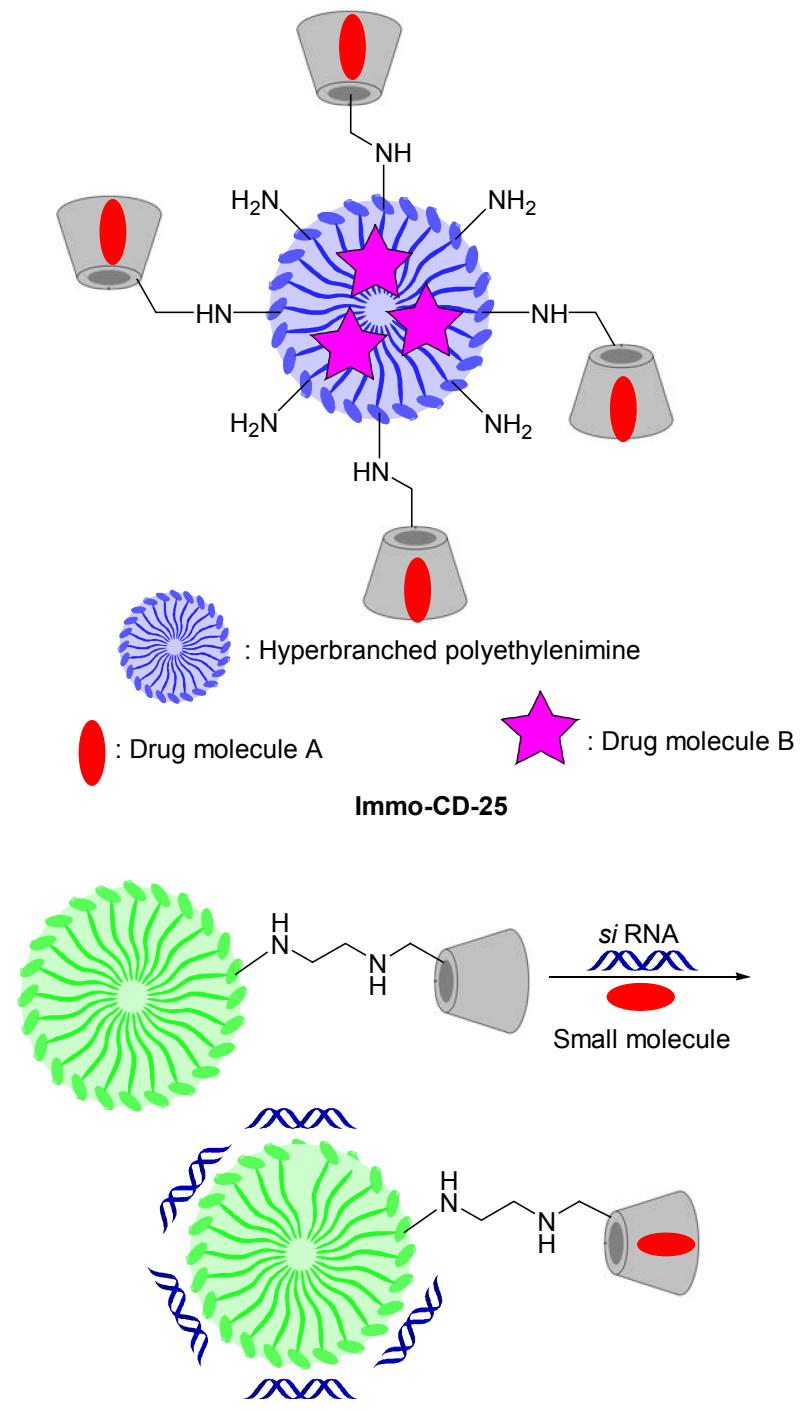

Immo-CD-26
以超支化聚甘油为载体固载 $\beta$-环糊精构筑药物分 子负载、输送和缓释材料, 也是 $\beta$-环糊精固载的一个重 要方向, Zhang 等 ${ }^{[877}$ 将 $\beta$-环糊精固载在超支化聚甘油共 聚物上，作为鼻腔胰岛素的输送和缓释载体. 该胰岛素 负载载体不仅具有较高的负载能力, 可负载其自身重量 $23 \%$ 的胰岛素, 并且生物兼容性好, 可很好地通过鼻腔 黏膜上皮, 增强胰岛素的吸收, 显著降低血糖浓度. 将 该药物分子输送和缓释载体用于疏水抗癌药物的负载、 输送和缓释，以抗癌药物紫杉醇为例，同样取得了令人 满意的结果 ${ }^{[88]}$.

\section{3 以天然产物高分子材料为载体}

$\beta$-环糊精固载在天然产物高分子材料上，构筑药物 分子负载、输送和缓释材料, 天然产物高分子载体主要 包括壳聚糖、葡聚糖、纤维素、玻尿酸等，固载的实现 主要是通过天然产物高分子材料表面的接枝技术. 该类 固载化 $\beta$-环糊精, 载体及 $\beta$-环糊精单元均为天然产物, 细胞毒性低, 生物兼容性好, 部分载体还具有一定的药 物分子负载和输送功能, 甚至靶向输送功能, 是一极具 应用前景的药物分子负载、输送和缓释材料. Sajomsang 等 ${ }^{[89-91]}$ 分别通过亚甲基和柠檬酸将 $\beta$-环糊精固载在壳 聚糖上, 为提高其亲水性向壳聚糖主链引入了缩水甘油 基三甲基氯化铵基团, 形成水溶性的 $\beta$-环糊精-壳聚糖 负载体系 Immo-CD-27 和 Immo-CD-28, 系统考察了 $\beta$ 环糊精与壳聚糖之间不同的连接基团，对其负载丁香酚 能力和粘膜粘附性能的影响. 以亚甲基为连接基团, 丁 香酚不仅可以包结在 $\beta$-环糊精的疏水空腔中，而且还可 以负载在壳聚糖骨架上，以柠檬酸为连接基团，丁香酚 趋向于负载在壳聚糖骨架上，包结于 $\beta$-环糊精疏水空腔 中的丁香酚较少，因而以亚甲基为连接基团的 $\beta$-环糊 精-壳聚糖负载体系具有更高的丁香酚负载能力. 并且 由于以亚甲基为连接基团的 $\beta$-环糊精-壳聚糖负载体系 在水相中易于自聚形成自聚体，其丁香酚的缓释性能也 优于以柠檬酸为连接基团. 在粘膜粘附实验中，以柠檬 酸为连接基团的 $\beta$-环糊精-壳聚糖体系与粘膜具有更强 的粘附性能, 这主要是由于二者之间的相互作用力不仅 有静电力相互作用，还有氢键相互作用，而以亚甲基为 连接基团的 $\beta$-环糊精-壳聚糖负载体系与粘膜之间的相 互作用仅为静电力相互作用. Ping 等 ${ }^{[92]}$ 以聚乙烯亚胺为 连接基团, 将 $\beta$-环糊精固载在壳聚糖上, 作为 DNA 和 siRNA 的输送载体, 取得了很好的效果, 可很好地将 DNA 和 siRNA 聚合成球型纳米粒子. 另外, 该输送载 体上的 $\beta$-环糊精单元还可以同具有合适官能团的聚乙 二醇形成主客体包结络合物，如金刚烷基修饰的聚乙二 醇，可显著提高该药物输送载体在体液中的稳定性. 另 外, Yuan 等 ${ }^{[93]}$ 也报道了将 $\beta$-环糊精固载在壳聚糖上, 通 
过离子凝胶法制得 $\beta$-环糊精一壳聚糖纳米粒子, 作为疏 水药物的输送和缓释载体, 负载和缓释酮洛芬, 效果也 十分明显.

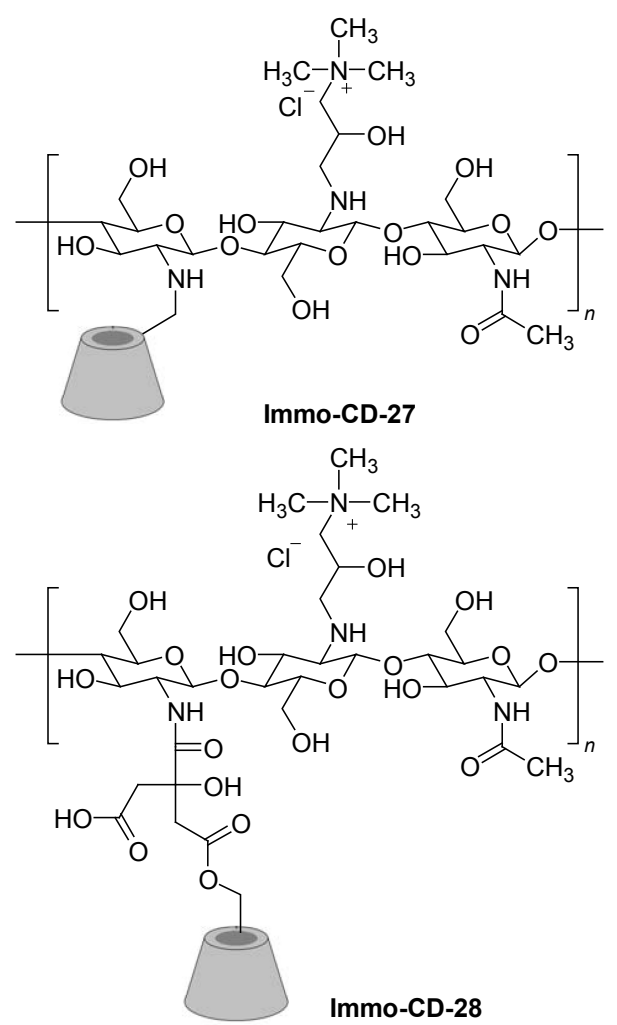

除了壳聚糖, Peng 等 ${ }^{[94]}$ 借助颈基与马来酰胺基团的 Michael 加成反应, 将包结有药物分子反式维甲酸的全 (6-脱氧-6-巯基)- $\beta$-环糊精固载在马来酰胺修饰的葡聚 糖上(Immo-CD-29), 形成凝胶, 构筑疏水药物分子的 负载和控制释放体系. 由于 $\beta$-环糊精单元对药物分子的 包结络合作用, 避免了药物分子在释放初期的剧烈释 放, 并以 $20 \mathrm{nmol} / \mathrm{d}$ 的释放速率持续释放 $14 \mathrm{~d}$. Li 等 ${ }^{[95]}$ 通过接枝有 $\beta$-环糊精单元的葡聚糖与接枝有金刚烷基 的聚天门冬氨酸主-客体相互作用, 构筑微胶囊负载药 物分子罗丹明 B. 由于 $\beta$-环糊精单元是通过对酸敏感的 亚胺基团接枝在葡聚糖上, 所以该微胶囊在酸性环境下 易于降解, 释放药物分子罗丹明 $\mathrm{B}$, 从而达到控制释放 的目的. 体外药物释放实验表明, 该微胶囊是一优良的 药物分子负载和控制释放载体.

对于纤维素类载体, Cravotto 等 ${ }^{[6]}$ 以六亚甲基-1,6二异氧酸酯为连接基团, 通过超声促进将 $\beta$-环糊精固载 在胶粘纤维上(Immo-CD-30), 借助 $\beta$-环糊精的主体包 结络合作用包结负载七叶皇苷制剂, 用于腿部静脉功能 不全的治疗. 通过猪皮肤的体外实验研究发现, 负载的 七叶㿝苷不仅可以通过皮肤进行渗透, 并在皮肤下积累 发挥疗效, 而且 $\beta$-环糊精单元释放出七叶㿝苷后, 可以 重新负载, 重复使用, 具有巨大的实际应用潜力. Kang

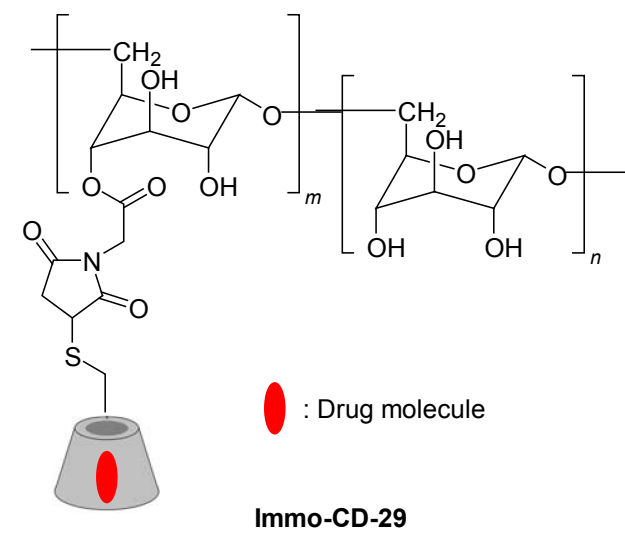

等 ${ }^{[97]}$ 以聚 $\varepsilon$-己内酯为连接基团, 借助 “Click” 反应将 $\beta$ 环糊精固载在乙基纤维素上, 实现 $\beta$-环糊精的固载 (Immo-CD-31). 该共聚物在水相中易于自聚形成胶束 粒子, 并且 $\beta$-环糊精单元位于胶束的表面. 通过循环伏 安法研究了该胶束同二茂铁衍生物的主一客体相互作用, 不仅证实了在自聚形成的胶束中, $\beta$-环糊精单元位于胶 束的表面，而且表明该自聚胶束具有用作分子识别性纳 米受体和药物负载及缓释载体的潜力.
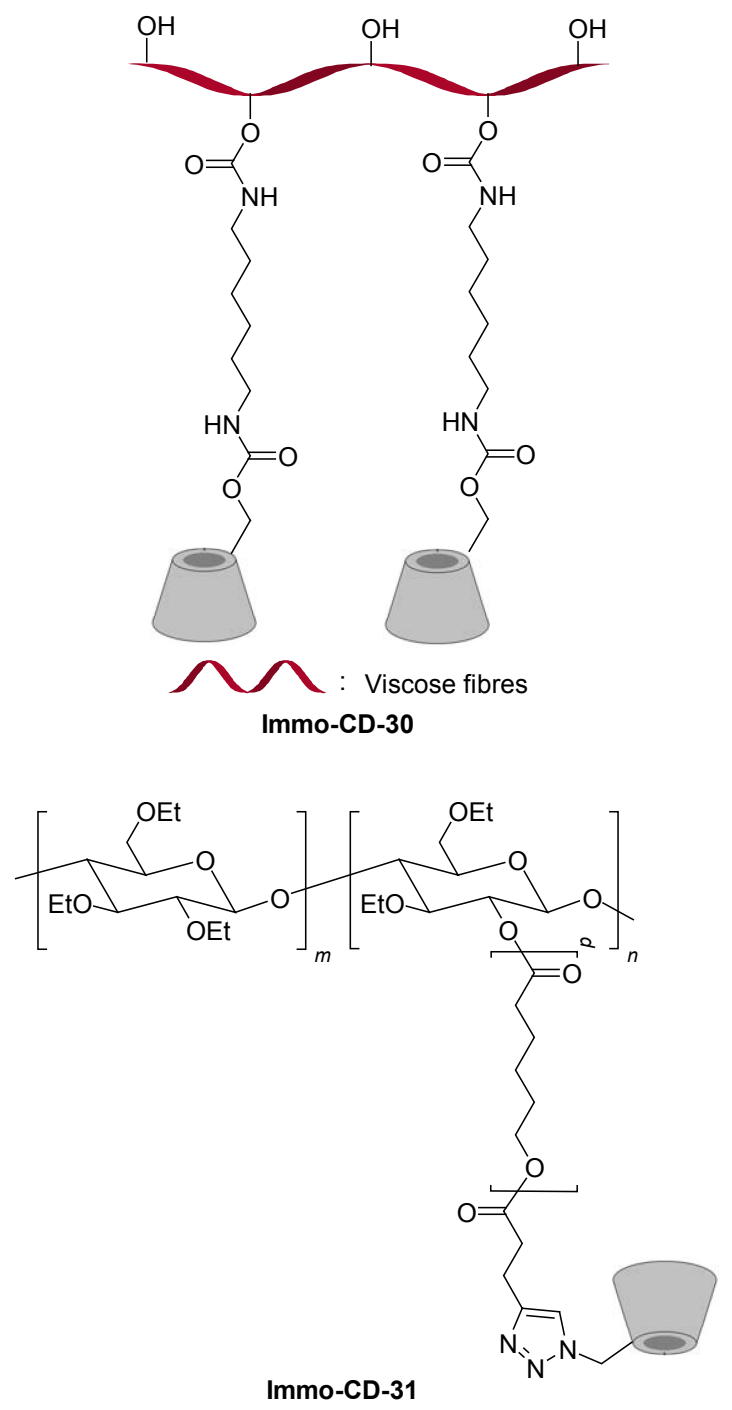

Immo-CD-31 
除了上述天然产物高分子作为载体，Yang 等 ${ }^{[98]}$ 还 借助 1-乙基-3-(3-二甲氨基丙基)羰基二咪唑(EDC)和 $N$ 羟基磺基琥珀酰亚胺钠(NHSS)的活化脱水作用, 将单 (6-脱氧-6-乙二胺基)- $\beta$-环糊精固载在玻尿酸上, 构筑靶 向药物输送载体 Immo-CD-32. 该药物分子靶向输送载 体兼具玻尿酸的癌细胞识别性能和 $\beta$-环糊精单元的药 物分子包结输送性能, 以抗癌药物分子 Adamplatin 为模 型化合物, 该药物输送体系取得了与市售抗癌药物 cisplatin 相似的药效, 但该药物输送体系在体内、体外 实验中，均具有更低的副作用，十分具有应用潜力.

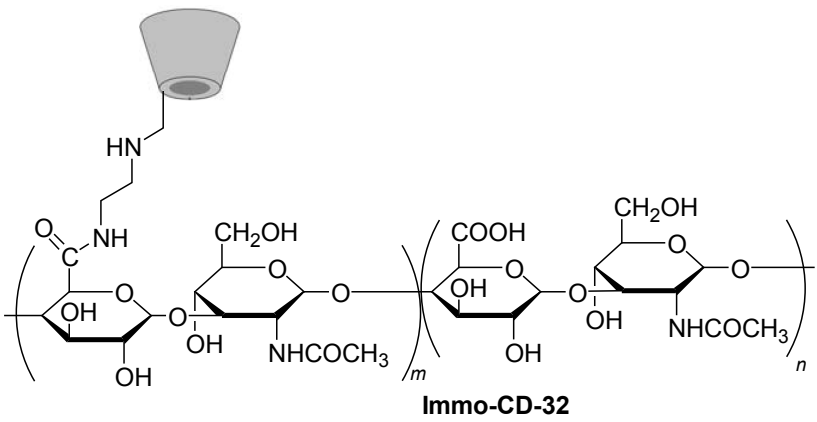

\section{4 以其它材料为载体}

除了以上三类主要载体外, 一些蛋白质和植物病毒 也被用来作为 $\beta$-环糊精的载体, 构筑药物分子负载、输 送和缓释载体, 如 Kwon 等 ${ }^{[99]}$ 通过 “Click” 反应将 $\beta$ 环糊精固载在人类重链铁蛋白形成的蛋白笼上 (Immo-CD-33), 包结输送和缓释疏水性药物分子. 该 药物输送缓释载体, 不仅可以高负载量地负载药物分 子, 并且与药物分子共价结合在蛋白笼上相比, 药物分 子的释放也相对容易, 负载和缓释效果均十分可观. Chen 等 ${ }^{[100]}$ 通过亲电取代反应和“ Click” 环加成反应, 将 $\beta$-环糊精固载在植物病毒 Tobacco mosaic virus 的表面 上(Immo-CD-34), 然后借助 $\beta$-环糊精单元与金刚烷基 的主一客体相互作用将金刚烷基团修饰的成像试剂、靶 向输送配体和化疗药物分子固载在 Tobacco mosaic virus 的表面, 提高药物输送的效率和药效, 取得了很好 的效果. 该类通过自聚集形成的超分子病毒纳米粒子在 临床诊断和治疗具有极大的应用潜力. 整体上说, 以蛋 白质聚集体和植物动物病毒作为 $\beta$-环糊精的载体, 构筑 药物分子负载、输送和缓释载体, 报道还比较少, 但由 于蛋白质与病毒往往具有特异性的结合部位, 构筑靶向 药物输送载体前景比较广阔.

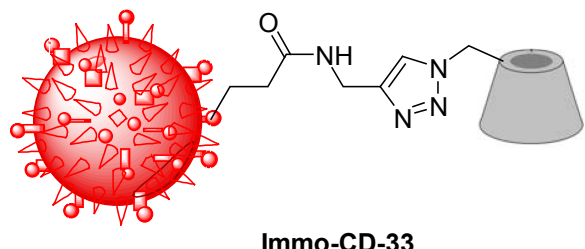

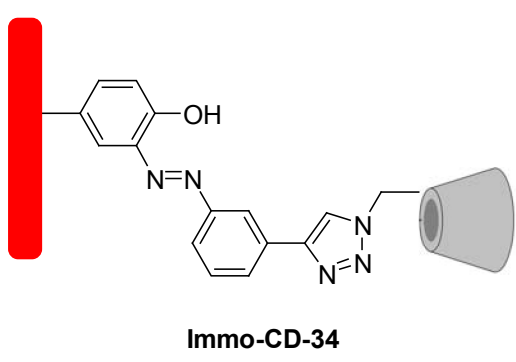

$\beta$-环糊精固载化构筑药物分子负载、输送和缓释载 体, $\beta$-环糊精除了扮演包结负载、输送、缓释等角色外, 在以介孔 $\mathrm{SiO}_{2}$ 为主体的药物分子负载、输送和缓释体系 中, $\beta$-环糊精还可以充当 “门卫” 的角色. 如 Kim 等 ${ }^{[101]}$ 通过二硫键和 “Click” 反应, 将 $\beta$-环糊精固载在介孔 $\mathrm{SiO}_{2}$ 纳米粒子的表面上(Immo-CD-35), 用以控制负载 在介孔 $\mathrm{SiO}_{2}$ 纳米粒子孔道中的药物分子的释放 (Scheme 1). 在谷胱甘肽的诱导下, 二硫键易于断裂, 使固载的 $\beta$-环糊精单元脱离介孔 $\mathrm{SiO}_{2}$ 的表面, 从而使负载在介 孔 $\mathrm{SiO}_{2}$ 纳米粒子孔道中的药物分子释放出来. Wang 等 ${ }^{[102 ~ 104]}$ 也报道了类似的研究, 对药物分子的控制性释 放具有重要的研究意义及应用价值.

由此可见，固载 $\beta$-环糊精构筑药物分子负载、输送 和缓释载体不仅保持了 $\beta$-环糊精单元本身的药物分子 包结负载、输送和缓释等特性, 还可以提升载体本身的 药物分子负载、输送和缓释性能及生物兼容性. 该类固 载化 $\beta$-环糊精使同时将多种活性成分负载于同一载体, 并且靶向输送到病变部位进行可控制地释放成为现实, 不仅提高治疗效果, 也可以减轻药物使用造成的副作 用. 因此，固载 $\beta$-环糊精构筑高负载量、靶向输送并且 生物兼容性好, 细胞毒性低, 且可控制释放的药物分子 负载、输送和缓释材料, 依旧是药物分子负载、输送和 缓释载体研究的热点.

\section{3 分析检测}

固载化 $\beta$-环糊精用于分析检测, 主要是借助固载化 $\beta$-环糊精构筑光学传感器、电化学传感器或其它生物/ 化学传感器, 借助 $\beta$-环糊精单元对被分析检测物质的包 结络合作用及分子识别性能, 达到被分析物质选择性地 富集在探针附近的目的, 从而引起光学信号或电化学信 号的显著变化. 该类传感器由于具备了 $\beta$-环糊精单元的 包结富集性能，往往可以达到极低的检测限，并且检测 速度快. 按照固载载体的不同, 在分析检测领域, $\beta$-环 糊精的固载可以分为直接以电极为载体、以非电极无机 材料为载体和以有机合成高分子材料为载体.

\section{1 以电极为载体}

$\beta$-环糊精固载在电极上, 构筑电化学传感器, 主要 

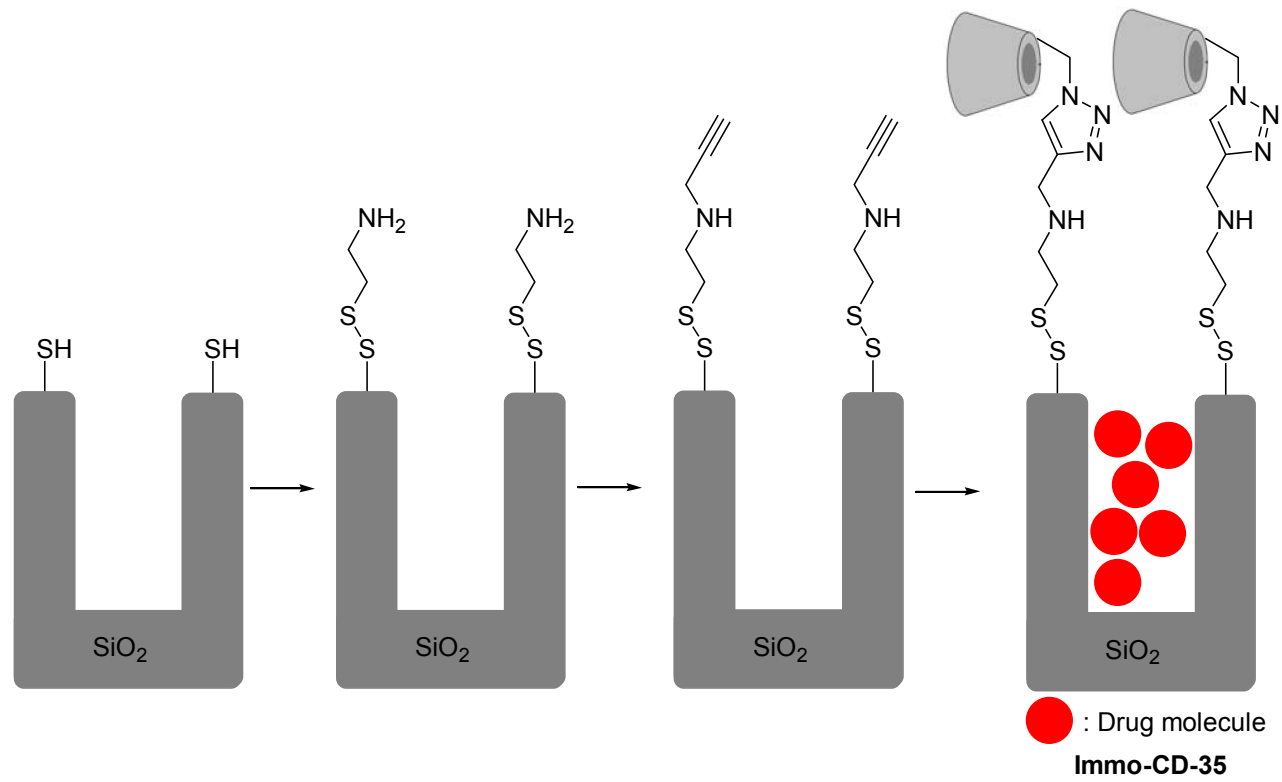

Scheme 1

是借助 $\beta$-环糊精单元对被分析检测物质的包结络合作 用及分子识别性能, 使被分析物质选择性地富集在电极 附近, 从而引起电化学信号的显著变化, 达到快速定性 定量检测的目的. 如 Huang 等 ${ }^{[105]}$ 将 6-脱氧-6-颈基- $\beta$-环 糊精固载在金电极上(Immo-CD-36), 与亚甲基绿形成 主-客体包结络合物, 构筑非酶胆固醇安培生物传感器, 检测胆固醇(Scheme 2). 当体系中存在胆固醇时, 由于 胆固醇与 $\beta$-环糊精单元具有更强的包结络合作用, 亚甲 基绿将会从 $\beta$-环糊精的疏水空腔中解离出来, 从而引起 电化学信号的变化, 高灵敏度, 高选择性检测胆固醇. 在胆固醇浓度为 $2.0 \times 10^{-8} \sim 5.0 \times 10^{-5} \mathrm{~mol} / \mathrm{L}$ 范围内, 均可给出线性信号, 最低检测限达到 $7.0 \times 10^{-9} \mathrm{~mol} / \mathrm{L}$, 在临床血样胆固醇含量检测中具有极大的应用潜力. $\mathrm{Yu}$ 等 ${ }^{[106]}$ 通过颈基将 $\beta$-环糊精固载在金纳隙电极的表面, 检测多氯联苯化合物. 由于 $\beta$-环糊精单元的疏水空腔可 以与多氯联苯化合物形成包结络合物, 对电荷转移形成 特异性的抑制作用, 可引起电导率可检测性的降低, 最 低检测限达到 $\mathrm{nmol} / \mathrm{L}$. Diez 等 ${ }^{[107]}$ 则通过半胱氨酸将 $\beta$ 环糊精固载在金电极上, 然后与金刚烷修饰的葡萄糖氧
化酶形成包结络合物, 该酶电极被用作无试剂安培生物 传感器，检测葡萄糖. 该生物传感器安培反应时间仅 6 $\mathrm{s}$, 在葡糖糖浓度为 $5 \sim 750 \mu \mathrm{mol} / \mathrm{L}$ 的范围内均可以给出 线性安培信号, 最低检测限为 $2.0 \mu \mathrm{mol} / \mathrm{L}, 4{ }^{\circ} \mathrm{C}$ 下储存 9 $\mathrm{d}$ 仍能保持其安培反应性能的 $94 \%$, 具有极好的选择 性、灵敏度和稳定性.

\section{2 以非电极无机材料为载体}

$\beta$-环糊精固载在非电极无机材料上，用于分析检 测, 主要是借助固载化 $\beta$-环糊精构筑光学传感器或以固 载化 $\beta$-环糊精修饰电极构筑电化学传感器, 借助 $\beta$-环糊 精单元对被分析检测物质的包结络合作用及分子识别 性能, 使被分析物质得到选择性地富集, 从而引起光学 信号或电化学信号的显著变化, 达到快速定性定量检测 的目的. 载体目前报道的有金属纳米粒子、石墨烯、碳 纳米管、富勒烯、量子点、 $\mathrm{SiO}_{2}$ 等. 如 Wang 等 ${ }^{[108]}$ 通过 颈基与 $\mathrm{Au}$ 纳米粒子的相互作用, 将单(6-脱氧-6-颈 基)- $\beta$-环糊精固载在一维金纳米粒子上，构筑光学传感 器 Immo-CD-37, 借助拉曼散射光谱检测环境样品中的

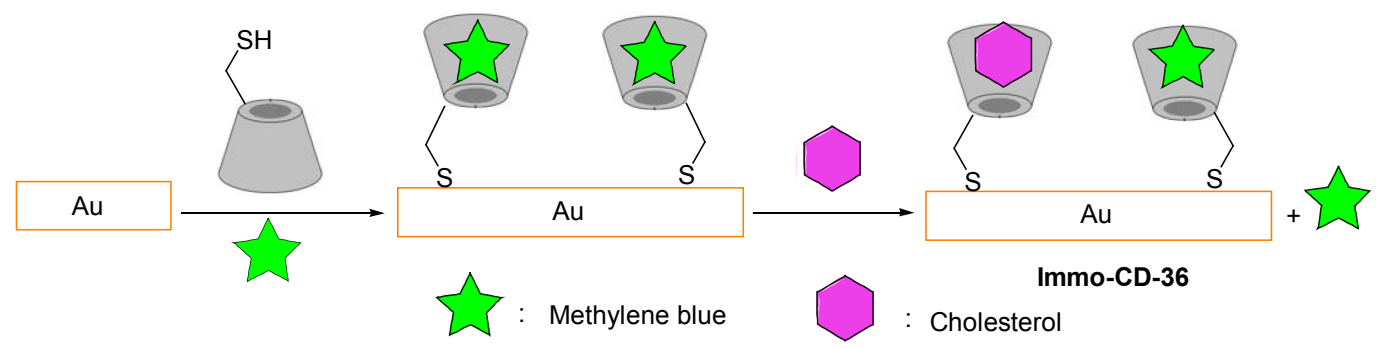

Scheme 2 
痕量农药, 如甲基对硫磷. 当一维金纳米粒子的纵横比 为 2 时, 该光学传感器检测甲基对硫磷表现出最佳的拉 曼散射增强效应. 由于 $\beta$-环糊精单元对甲基对硫磷的包 结富集作用, 该光学传感器表现出极高的灵敏度和选择 性, 可以通过拉曼散射指纹峰检测和识别皮摩尔级的农 药残留. 同传统检测方法相比, 该方法更简单, 更灵敏, 在环境样品检测中具有极大的应用前景. Xie 等 ${ }^{[109]}$ 通过 颈基与 $\mathrm{Ag}$ 纳米粒子的相互作用, 将全(6-脱氧-6-颈 基) $\beta$-环糊精固载在 $\mathrm{Ag}$ 纳米粒子上, 构筑光学传感器

Immo-CD-38, 通过拉曼光谱检测环境污染物多环芳烃, 如葱和萠. 由于 $\beta$-环糊精单元的主体识别性能, 不仅显 著增强了该光学传感器的灵敏度, 而且还可以根据特征 峰的不同区分多环芳烃, 并定量检测多环芳烃. 因此, 该光学传感器具有广泛应用于环境监测领域的潜力. Chen 等 ${ }^{[110]}$ 以 $\beta$-环糊精修饰 $\mathrm{Ag}$ 纳米粒子, 然后以该纳 米粒子修饰铟锡氧化物电极, 构筑电化学传感器检测硝 基苯胺异构体及氯代硝基苯异构体. 在相同的检测条件 下, 各硝基苯异构体表现出各自特征的还原电压信号, 可以方便地进行区分, 最低检测限达到了 $1.0 \times 10^{-7}$ $\mathrm{mol} / \mathrm{L}$. 同时, 由于 $\beta$-环糊精单元的分子识别性能, 该化 学传感器对 4-硝基苯胺和 1-氯-2-硝基苯表现出特异的 高选择性识别能力. Zhang 等 ${ }^{[111]}$ 则以颈基化 $\beta$-环糊精修 饰 $\mathrm{Pt}$ 纳米粒子, 实现了 $\beta$-环糊精在 $\mathrm{Pt}$ 纳米粒子上的固 载, 然后以该固载化 $\beta$-环糊精修饰 $\mathrm{Au}$ 电极, 借助 $\beta$-环 糊精单元与金刚烷基的主-客体包结络合作用将胆碱氧 化酶和辣根过氧化物酶固载在该金电极的表面, 构筑生 物传感器, 检测胆碱分子. 在胆碱的浓度为 $10^{-9} \sim 10^{-2}$ $\mathrm{mol} / \mathrm{L}$ 内, 均可以给出线性的电化学响应信号, 最低检 测限达到了 $0.1 \mathrm{nmol} / \mathrm{L}$, 效果很好.

石墨烯也是 $\beta$-环糊精固载, 构筑电化学传感器的优 良载体, 由于石墨烯的高比表面积和优良的电化学性能 及 $\beta$-环糊精单元的分子识别性包结络合作用, 以 $\beta$-环糊 精-石墨烯体系修饰电极构筑的电化学传感器具有极高 的灵敏性和选择性. 如 Xu 等 ${ }^{[112]}$ 通过微波促进法将羟丙 基 $\beta$-环糊精固载在化学还原的石墨烯上, 并以此固载化 $\beta$-环糊精修饰玻碳电极, 构筑电化学传感器. 由于该传 感器兼具石墨烯的高比表面积和 $\beta$-环糊精单元的分子 识别性能, 可以高灵敏度的识别检测一系列苯酚类环境 污染物, 如硝基苯酚、氯代苯酚、甲基苯酚等. 以 $o$-硝 基苯酚为例, 在浓度为 $5.0 \times 10^{-8} \sim 1.0 \times 10^{-4} \mathrm{~mol} / \mathrm{L}$ 范 围内, 均可以给出线性的氧化电压信号, 最低检测限达 到了 $1.0 \times 10^{-8} \mathrm{~mol} / \mathrm{L}$. Mondal 等 ${ }^{[113]}$ 则借助 $\beta$-环糊精的 羟基与石墨烯环氧基团的反应, 将 $\beta$-环糊精共价固载在 石墨烯上, 并与罗丹明 $6 \mathrm{G}$ 形成包结络合物, 构筑化学 传感器 Immo-CD-39, 检测胆固醇分子(Eq. 2). 由于石

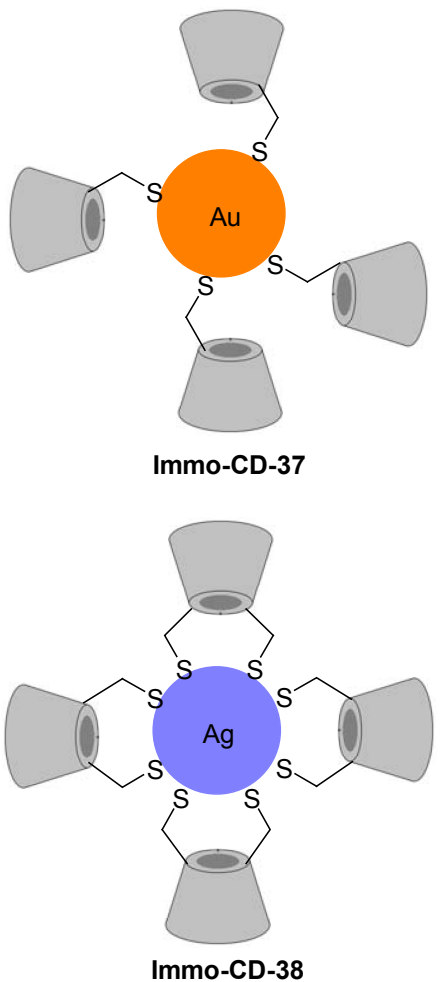

墨烯对罗丹明 $6 \mathrm{G}$ 荧光的淬灭作用，当罗丹明 $6 \mathrm{G}$ 包结在 $\beta$-环糊精的疏水空腔时，无法给出明显的苂光信号. 当 体系中存在胆固醇分子时, 由于 $\beta$-环糊精与胆固醇分子 具有更强的亲和力，使罗丹明 $6 \mathrm{G}$ 释放到溶液中，进而 表现出苂光性质。该过程可高灵敏度地检测胆固醇分子 而不使用到胆固醇相关的酶或抗体，使用方便. 除了共 价键合, Guo 等 ${ }^{[114]}$ 主要以氢键相互作用将 $\beta$-环糊精固载 在石墨烯上(Immo-CD-40), 并以此固载化 $\beta$-环糊精修 饰玻碳电极, 构筑电化学传感器检测杀菌剂多菌灵. 在 多菌灵的浓度为 $5 \mathrm{nmol} / \mathrm{L} \sim 0.45 \mu \mathrm{mol} / \mathrm{L}$ 范围内, 均可以 给出线性的电流信号, 最低检测限达到了 $2 \mathrm{nmol} / \mathrm{L}$. Liu 等 ${ }^{[115]}$ 也报道了通过非共价相互作用将 $\beta$-环糊精固载在 石墨烯上, 修饰玻碳电极, 构筑电化学传感器检测 $o$-硝 基苯酚, 在 $o$-硝基苯酚的浓度为 $5 \sim 400 \mu \mathrm{mol} / \mathrm{L}$, 均可 以给出线性的还原电压信号, 最低检测限达到了 0.3 $\mu \mathrm{mol} / \mathrm{L}$, 而不受其它硝基苯酚异构体 ( $p$-硝基苯酚和 $m$ 硝基苯酚)存在的影响，特异性好，并成功应用于湖水 样品的分析检测，稳定性和检测重现性良好.

与石墨烯相似，碳纳米管也广泛用来固载 $\beta$-环糊 精, 并用来修饰电极, 构筑电化学传感器. 如 Kong 等 ${ }^{[116]}$ 以 $p$-苯二胺为连接基团, 将 $\beta$-环糊精固载在单层 碳纳米管上(Immo-CD-41), 并以该固载化 $\beta$-环糊精修 饰金电极, 构筑电化学传感器，检测环境中有机污染物 如 2,4,5-三氯联苯，取得了很高的灵敏度，还具有很高 的选择性. Yang 等 ${ }^{[117]}$ 通过重氮化反应，将 $\beta$-环糊精固 载在定向碳纳米管上，以此固载化 $\beta$-环糊精修饰玻碳电 


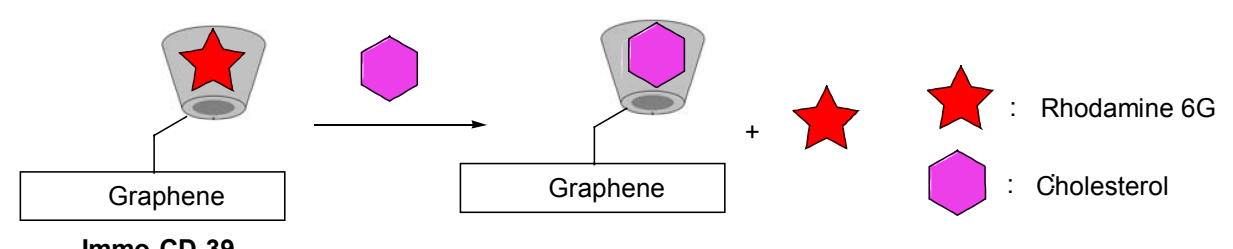

Immo-CD-39

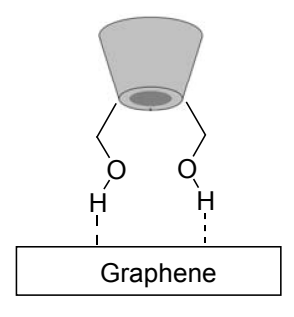

Immo-CD-40

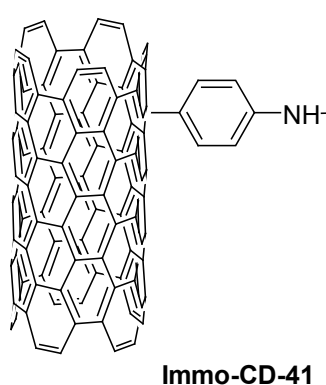

Immo-CD-41

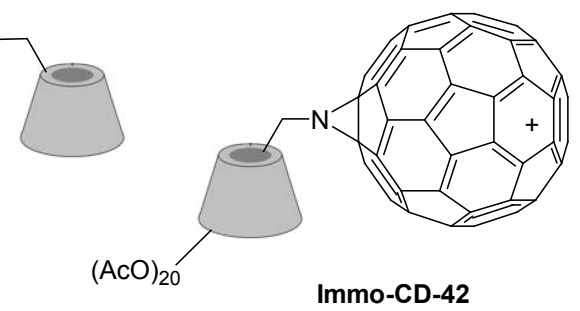

精-CdSe 量子点的苂光淬灭效应，对多元酸来说，一价 阴离子的淬灭效应最强. 除此以外，一些重金属离子和 过渡金属离子 $\mathrm{Ag}^{+}, \mathrm{Hg}^{2+}$ 和 $\mathrm{Co}^{2+}$ 也可以引起 $\beta$-环糊精$\mathrm{CdSe}$ 量子点的荧光淬灭效应. 说明该 $\beta$-环糊精- $\mathrm{CdSe}$ 量 子点可用作上述阴离子和阳离子检测的探针, 用于低浓

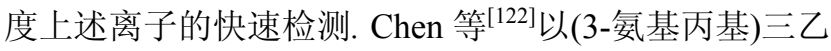
氧基硅烷为连接基团, 将 $\beta$-环糊精固载在 $\mathrm{CdTe}$ 量子点 上(Immo-CD-44), 构筑苂光探针识别检测 1,1,1-三氯2-(o-氯苯基)-2-( $p$-氯苯基 $) 乙$ 烷 $\left(o, p^{\prime}\right.$-DDT) 和 1,1,1-三氯2,2 -双-( $p$-氯苯基)乙烷 $\left(p, p^{\prime}\right.$-DDT). 该化学传感器兼具 $\mathrm{CdTe}$ 量子点的光学性能和 $\beta$-环糊精单元的分子识别性 能, 对 $o, p^{\prime}$-DDT 表现出极高的分子识别性检测能力, 荧 光淬灭强度与 $o, p^{\prime}$-DDT 的浓度表现出很好的线性相关 性, 而对 $p, p^{\prime}$-DDT 却未表现出明显的荧光信号变化, 选 择性强, 具有应用于实际样品检测的潜力. Cao 等 ${ }^{[123]}$ 则 通过颈基将 $\beta$-环糊精固载在 $\mathrm{CdSe}$ 量子点上 (Immo-CD-45), 借助量子化学计算和苂光光谱研究了 $\beta$-环糊精- $\mathrm{CdSe}$ 量子点体系对酪氨酸的分子识别性能. 虽然 $\beta$-环糊精- $\mathrm{CdSe}$ 量子点体系与酪氨酸的 $L$-和 $D$-构型 均可以形成包结络合物, 但与 $L$-构型的酪氨酸形成的包 结络合物更稳定, 表现出明显的分子识别性能. 在 $L$-酪 氨酸的浓度为 $0.10 \times 10^{-4} \sim 4.00 \times 10^{-4} \mathrm{~mol} / \mathrm{L}$ 时, $L$-酪氨

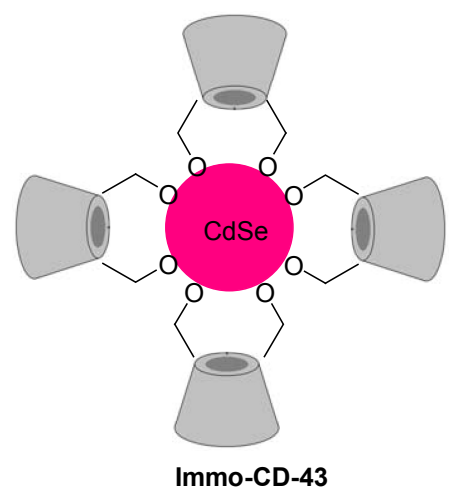

http://sioc-journal. cn/ 


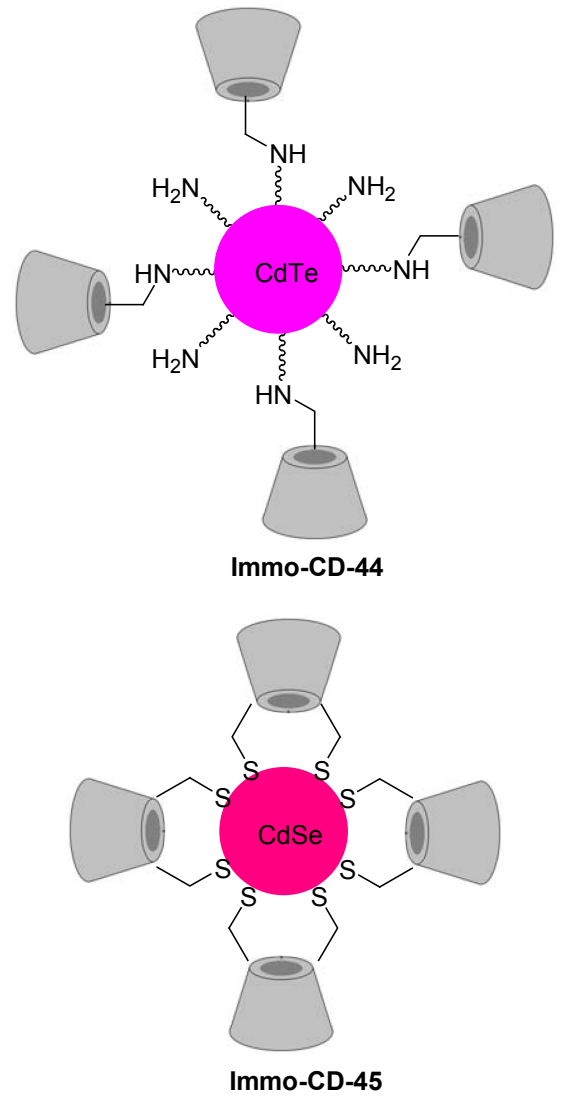

酸与 $\beta$-环糊精- $\mathrm{CdSe}$ 量子点体系的包结络合物均可以给 出线性的荧光强度信号.

另外, $\mathrm{Xu}$ 等 ${ }^{[124]}$ 还报道了以(3-缩水甘油氧基丙基)三 甲氧基硅烷为连接基团, 将 $\beta$-环糊精固载在介孔 $\mathrm{SiO}_{2}$ 上(Immo-CD-46), 并以此固载化 $\beta$-环糊精修饰碳糊电 极, 构筑电化学传感器检测硝基苯酚异构体. 由于 $\beta$-环 糊精单元的分子识别性捕获, 该化学传感器对 $o$-硝基苯 酚、 $m$-硝基苯酚和 $p$-硝基苯酚表现出不同的还原电压信 号, 在 $o$-硝基苯酚的浓度为 $2.0 \times 10^{-7} \sim 1.4 \times 10^{-6}$ $\mathrm{mol} / \mathrm{L} 、 m$ - 硝基苯酚的浓度为 $2.0 \times 10^{-7} \sim 1.6 \times 10^{-6}$ $\mathrm{mol} / \mathrm{L}$ 和 $p$-硝基苯酚的浓度为 $2.0 \times 10^{-7} \sim 1.4 \times 10^{-6}$ $\mathrm{mol} / \mathrm{L}$ 范围内均可以给出线性的电化学信号, 最低检测 限分别达到了 $1.0 \times 10^{-8} \mathrm{~mol} / \mathrm{L}$ ( $o$-硝基苯酚和 $p$-硝基苯 酚)和 $5.0 \times 10^{-8} \mathrm{~mol} / \mathrm{L}$ ( $m$-硝基苯酚), 表现出极高的选 择性和灵敏度, 可用于水相中硝基苯酚异构体的快速检 测.

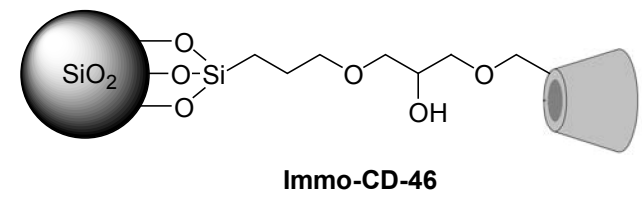

\section{3 以有机合成高分子材料为载体}

$\beta$-环糊精固载在有机合成高分子材料上，构筑电化 学传感器或光学传感器, 同以无机材料为载体相比, 报
道相对还比较少，载体有聚对苯二甲酸酯、聚氨基酸、 酚醛树脂等. Han 等 ${ }^{[125]}$ 通过酰胺键将 $\beta$-环糊精固载在聚 对苯二甲酸乙二酯膜(PTE)材料的纳米通道中(ImmoCD-47), 通过离子电流信号考察了该固载化 $\beta$-环糊精 对氨基酸类化合物的分子识别性能，该固载化 $\beta$-环糊精 对 $L$-组氨酸表现出显著的分子识别性能，离子电流信号 显著降低，而对 $D$-组氨酸及其它氨基酸未观察到离子 电流的变化, 是一性能优异的 $L$-组氨酸识别检测传感 器. Zhang 等 ${ }^{[126]}$ 通过电化学聚合的方法将 $\beta$-环糊精和 $L$ 精氨酸聚合, 修饰碳糊电极, 构筑化学传感器检测氟喹 诺酮类抗生素. 由于 $\beta$-环糊精单元可以与氟喹诺酮类化 合物形成主-客体包结络合物, $L$-精氨酸分子中的胍基 可以与氟喹诺酮类化合物中的羧基产生相互作用，二者 的协同效应显著提高了该生物传感器检测氟喹诺酮类 化合物的性能. 氧化电压与氟喹诺酮类抗生素的浓度, 在环丙沙星的浓度为 $0.05 \sim 100 \mu \mathrm{mol} / \mathrm{L}$, 氟诺沙星的浓 度为 $0.1 \sim 100 \mu \mathrm{mol} / \mathrm{L}$, 氧氟沙星的浓度为 $0.1 \sim 40$ $\mu \mathrm{mol} / \mathrm{L}$, 加替沙星的浓度为 $0.06 \sim 100 \mu \mathrm{mol} / \mathrm{L}$ 中, 均成 线性关系. 另外, 该化学传感器检测结果重现性、稳定 性和灵敏性均表现出令人满意的结果.

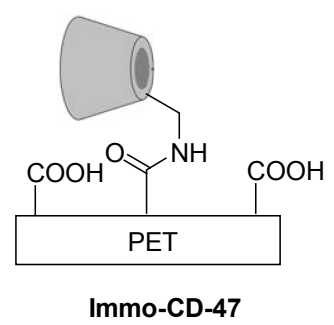

除了构筑电化学传感器, Maffeo 等 ${ }^{[127]}$ 借助十一碳 酸-10-烯为连接基团, 将甲基化 $\beta$-环糊精固载在 $\mathrm{Si} / \mathrm{SiO}_{2} /$ 酚醛树脂表面上, 构筑光学传感器, 通过白光反射光谱 检测杀菌剂三氯生, 最低检测限达到 $10 \mathrm{nmol} / \mathrm{L}$, 并且 该光学传感器非复杂的界面化学、非含硫 $\beta$-环糊精、非 金表面、设备简单，使其在捕获检测有机小分子化合物 等领域具有广泛的应用前景. $\mathrm{Liu}$ 等 ${ }^{[128]}$ 以马来酸䣲修饰 的 $\beta$-环糊精和丙烯酸为功能单体, $L$-苯丙氨酸为模板化 合物，聚合合成了分子印迹聚合物 Immo-CD-48，作为 光学传感器识别检测 $L$-苯丙氨酸(Scheme 3). 在 $L$-苯丙 氨酸的浓度为 $10^{-8} \sim 10^{-4} \mathrm{~mol} / \mathrm{L}$ 范围内, 该传感器检测 到的衍射波长变化均与 $L$-苯丙氨酸的浓度呈现良好的 函数关系，而对 $D$-苯丙氨酸、 $L$-络氨酸和 $L$-色氨酸未表 现出明显的识别检测性能, 特异性强. 该传感器可以成 功用于检测市售氨基酸注射剂中的 $L$-苯丙氨酸的含量.

由此可见，基于固载化 $\beta$-环糊精构筑光学传感器、 电化学传感器和生物传感器, 已广泛渗透到分析检测的 各个领域，尤其是快速检测. $\beta$-环糊精单元的存在，使 

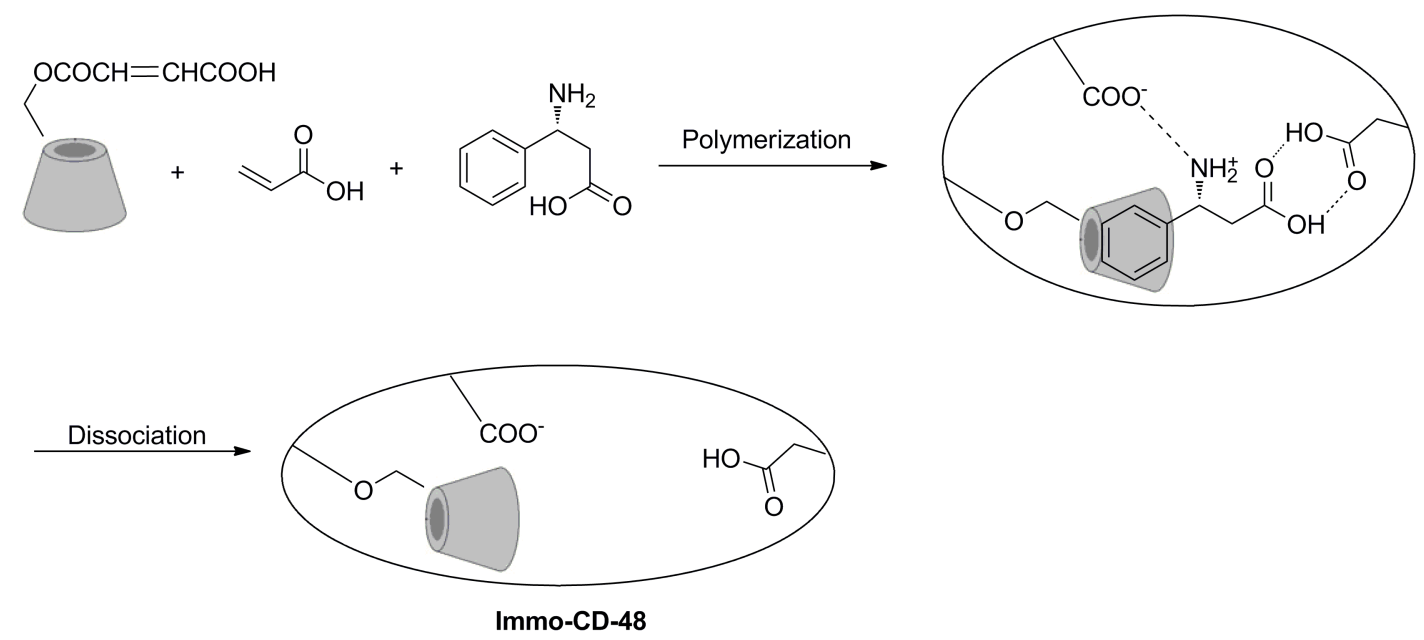

Scheme 3

被分析成分迅速高选择性地富集在检测探针附近, 并增 强探针在水溶液中的润湿性, 从而引起光学信号或电化 学信号的显著变化, 使构筑的传感器具有极高的灵敏性 和选择性. 另外, 该类传感器设备相对简单、成本低、 操作方便、分析检测速度快, 信号明显, 今后仍将具有 极大的研究价值和广阔的应用前景.

\section{4 手性分离}

固载 $\beta$-环糊精用于手性分离, 主要是基于 $\beta$-环糊精 单元特定的空腔结构及固有的手性本质, 借助 $\beta$-环糊精 单元与外消旋体中两种构型不同的包结络合特性, 即亲 和性, 实现外消旋体的对映选择性分离. 固载使用的载 体基本为 $\mathrm{SiO}_{2}$ 粒子, 其它载体的报道相对比较少. 按用 途的不同，固载 $\beta$-环糊精在手性分离领域的应用可分为 手性色谱柱分离、包结分离和膜分离, 其中在手性色谱 柱分离领域，固载化 $\beta$-环糊精应用最广.

\section{1 手性色谱柱分离}

固载化 $\beta$-环糊精在手性色谱柱分离领域的应用, 主 要是将 $\beta$-环糊精固载在 $\mathrm{SiO}_{2}$ 粒子上, 构筑手性色谱柱固 定相, 借助 $\beta$-环糊精单元与外消旋体中两种构型不同的 包结络合特性, 实现外消旋体的对映选择性分离. 如 $\mathrm{Ai}$ 等 ${ }^{[129]}$ 通过硫醇与烯烃的自由基加成反应, 将苯基氨基 甲酰化的 $\beta$-环糊精固载在介孔 $\mathrm{SiO}_{2}$ 粒子上(Immo-CD49), 用作超高压液相色谱柱手性固定相, 成功实现了 氨鲁米特、地尔硫卓、普萗洛尔等六个手性化合物的对 映选择性分离, 并且分离速度快, $10 \mathrm{~min}$ 内就可以实现 基线分离. $\mathrm{Li}$ 等 ${ }^{[130]}$ 则报道了以 Immo-CD-49 为毛细管 电色谱的手性固定相, 成功实现了一系列卤代芳基醇和 $\beta$-受体阻滞剂如普萗洛尔和吲哚洛尔的快速、基线、对 映选择性分离, 对 4-碘苯基-1-乙醇来说, 理论塔板数达 到了 476000/米, 是一性能优异的毛细管电色谱的手性
固定相. Chelvi 等 ${ }^{[131]}$ 将部分羟基被溴乙酸酯化的 $\beta$-环糊 精固载在硅胶粒子上，作为高效液相色谱柱的手性固定 相 Immo-CD-50, 成功实现了一系列芳香族位置异构体 的分离, 如 $o, m, p$-硝基苯酚和 $o, m, p$-硝基苯胺, 和一系 列手性分子的对映选择性分离, 如氨鲁米特、1-苯基2-丙醇、纳多洛尔、异丙嗪等. Wang 等 ${ }^{[132]}$ 通过 “Click” 反应, 分别将全苯基氨基甲酯化的 $\beta$-环糊精和全甲基化 $\beta$-环糊精固载在硅胶粒子上，作为手性高效液相色谱柱 的固定相 Immo-CD-51. 其中, 以全苯基氨基甲酯化的 $\beta$-环糊精为手性选择单元, 对映选择性分离效果最佳, 成功用于一系列外消旋的芳基醇、黄酮类化合物、芐氟 噻嗪、阿托品和一些 $\beta$-受体阻滞剂的对映选择性分离. 全甲基化 $\beta$-环糊精作为手性选择单元，虽然对考察的大 多数外消旋化合物未取得对映选择性分离, 但是对非芳 香族紫罗兰酮衍生物表现出对映选择性分离的性能. 除 此以外, Yuan 等 ${ }^{[133]}$ 通过自由基共聚, 将硫酸化 $\beta$-环糊 精固载在硅胶粒子上, 作为毛细管电色谱的手性固定 相; Zhao 等 ${ }^{[134]}$ 将利福霉素修饰的 $\beta$-环糊精固载在硅胶 粒子上，作为高效液相色谱柱的手性固定相; $\mathrm{Li}$ 等 ${ }^{[135]}$ 将 单(6-脱氧-6-(2,4-二羟基)苯甲亚氨基)- $\beta$-环糊精固载在 硅胶粒子上，作为高效液相色谱手性固定相; $\mathrm{Li}$ 等 ${ }^{[136]}$ 以 (3-缩水甘油氧基丙基)三甲氧基硅烷为连接基团, 分别 将单(6-脱氧-6-苯甲亚氨基)- $\beta$-环糊精和单(6-脱氧-6-苯 基亚氨基)- $\beta$-环糊精固载在硅胶粒子上，作为高效液相 色谱手性固定相; Wang 等 ${ }^{[137]}$ 通过原子转移自由基聚合 和 “Click” 反应, 将 $\beta$-环糊精固载在硅胶粒子上，作为 高效液相色谱柱的手性固定相; Zhang 等 ${ }^{[138]}$ 通过烷氧基 硅烷的缩聚反应和乙烯基的共聚反应，“一锅法” 将 $\beta$ 环糊精全苯胺基甲酸酯固载在硅板上，作为毛细管液相 色谱柱的手性固定相; Wang 等 ${ }^{[139]}$ 通过烯烃聚合反应将 $\beta$-环糊精固载在硅胶粒子上, 作为超临界流体色谱填充 
柱的手性固定相, 均取得了优异的对映选择性分离效 果.

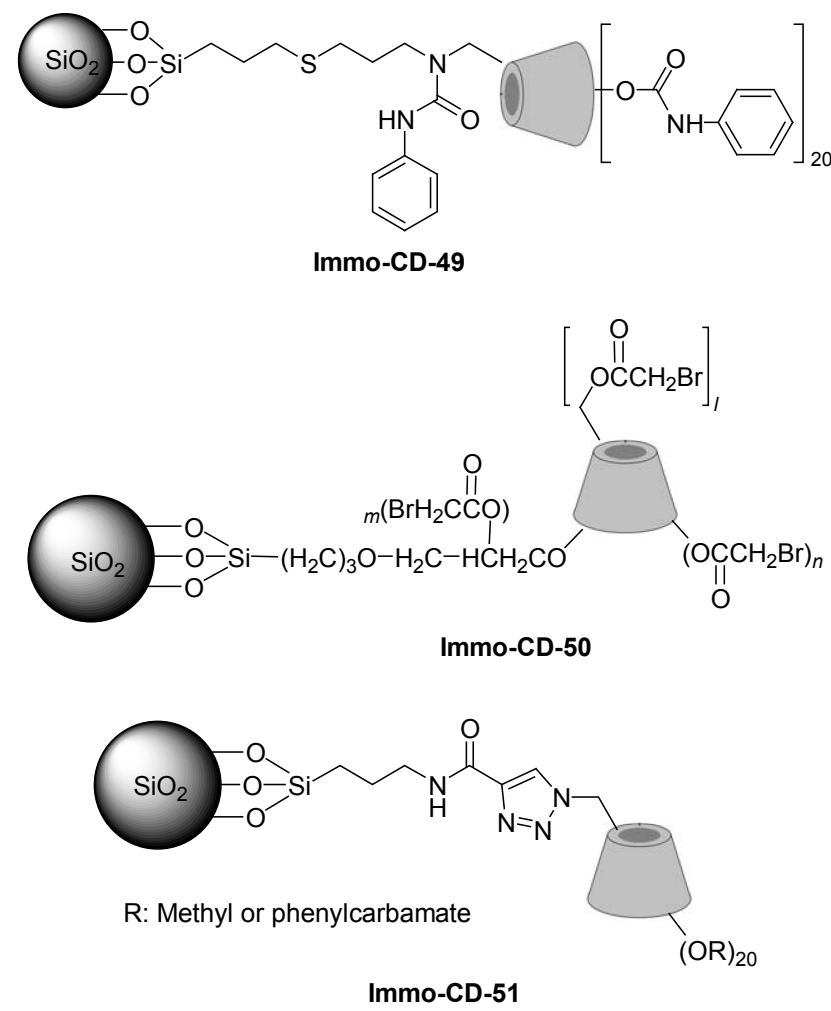

除了固载 $\beta$-环糊精, $\mathrm{Ai}$ 等 ${ }^{[140]}$ 通过 “Click” 反应将 $\alpha$ 环糊精固载在硅胶粒子上(Immo-CD-52), 作为 $5 \mathrm{~cm}$ 色 谱柱的填料, 对映选择性地分离丹磺酰基- $D, L$-氨基酸 及其它外消旋体. 借助 $\alpha$-环糊精的分子识别性能, 该手 性分离色谱柱在 $10 \mathrm{~min}$ 内可以完全或基本将 10 对丹磺 酰基- $D, L$-氨基酸对映选择性分离, 表现出优异的手性 分离性能.

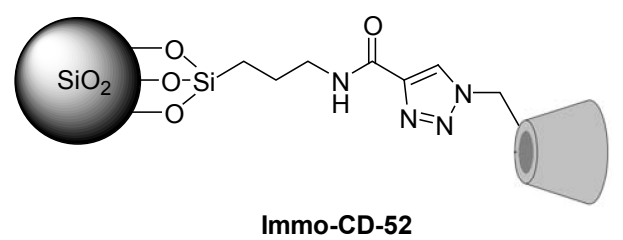

除了 $\mathrm{SiO}_{2}$ 粒子作为载体, $\mathrm{Lv}$ 等 ${ }^{[141]}$ 还以乙二胺为连 接基团, 将 $\beta$-环糊精固载在甲基丙烯酸缩水甘油酯和乙 二醇二甲基丙烯酸酯共聚物(GMA-co-EGDMA)上 (Immo-CD-53), 作为手性分离固定相手性分离布洛芬 异构体, 由于 $\beta$-环糊精单元的分子识别性能, $6 \mathrm{~min}$ 就可 以实现布洛芬两种构型异构体的快速基线分离. $\mathrm{Li}$ 等 ${ }^{[142]}$ 借助巯基将 $\beta$-环糊精固载在金纳米粒子上，并以 此固载化 $\beta$-环糊精作为开管毛细管电色谱的固定相, 实 现了 3 个外消旋药物分子的基线分离. 但整体上, 在手 性色谱柱分离领域, $\mathrm{SiO}_{2}$ 粒子还是 $\beta$-环糊精固载的主流
载体.

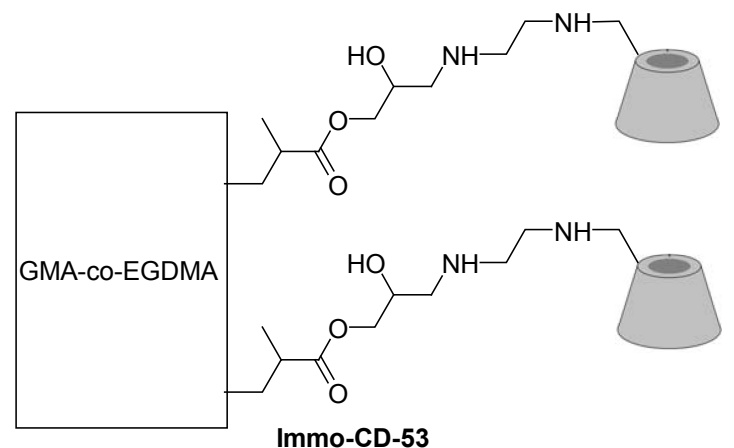

\section{2 包结分离}

固载化 $\beta$-环糊精用于包结分离, 原理与色谱柱分离 相同，借助 $\beta$-环糊精单元与外消旋体中两种构型不同的 包结络合特性，使外消旋体的一种构型选择性地包结在 固载化 $\beta$-环糊精上，而另一构型则保留在母液中，实现 两种构型的分离. 但这种分离方式, 很难实现两种构型 的彻底分离. 固载的载体也以 $\mathrm{SiO}_{2}$ 为主. 如 $\mathrm{He}$ 等 ${ }^{[143]}$ 以 (3-缩水甘油氧基丙基)三甲氧基硅烷为连接基团, 将 $L$ 苯丙氨酸修饰的 $\beta$-环糊精固载在 $\mathrm{SiO}_{2}$ 粒子上 (Immo-CD-54), 作为吸附分离材料吸附分离丙氨酸外 消旋体. $L$ - 苯丙氨酸修饰基团的引入，显著增强了 $\beta$-环 糊精单元的分子识别能力. $25{ }^{\circ} \mathrm{C}$ 下, 该吸附材料对 $L$-丙 氨酸和 $D$-丙氨酸的饱和吸附量分别为 59.26 和 26.64 $\mathrm{mg} / \mathrm{g}$, 选择性吸附 $L$-丙氨酸效果明显, 选择因子最高达 到 2.53. 因此，该吸附分离材料可应用于拆分外消旋的 丙氨酸外消旋体. Zhu 等 ${ }^{[144]}$ 通过(3-氨基丙基)三甲氧基 硅烷、戊二醛、聚乙烯醇等为连接基团, 将 $\beta$-环糊精固 载在硅胶粒子上，作为吸附材料吸附拆分手性药物分 子. 以扁桃酸作为模型化合物，由于聚乙烯醇的引入， 该吸附材料对扁桃酸的饱和吸附容量达到了 $\beta$-环糊精 直接固载在硅胶粒子上的 3 倍, 手性拆分外消旋扁桃酸 的产物 $e e$ 值也由 $6.04 \%$ 提高到 $18.28 \%$. 该吸附拆分材料 较大的吸附容量和较好的拆分选择性，使其具有大规模 应用于手性药物拆分的潜力. 除此以外, Lai 等 ${ }^{[145]}$ 以(3缩水甘油氧基丙基)三甲氧基硅烷为连接基团，将 $\beta$-环 糊精固载在硅胶粒子上(Immo-CD-46), 用于包结分离 绿茶提取物中的没食子儿茶素没食子酸酯. 由于 $\beta$-环糊 精的分子识别性能，同绿茶提取物中的其它组分相比， 该固载化 $\beta$-环糊精对没食子儿茶素没食子酸酯表现出 更强的包结络合性能，饱和包结络合量达到了 $55 \mathrm{mg} / \mathrm{g}$. 以该固载化 $\beta$-环糊精作为制备性色谱柱固定相，分离绿 茶提取物各组分, 没食子儿茶素没食子酸酯保留性能最 强，分离出来的没食子儿茶素没食子酸酯纯度达到 $90 \%$, 回收率达到 $90 \%$, 具有用作大规模制备性柱分离 
固定相的潜力.

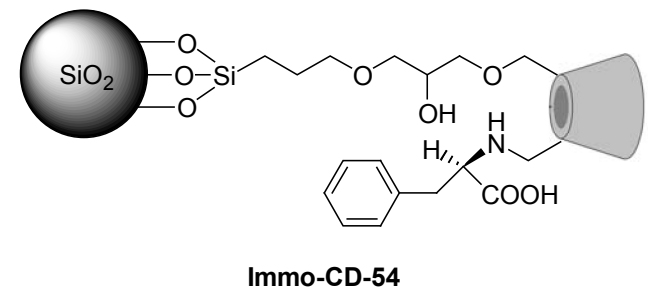

\section{3 膜分离}

固载化 $\beta$-环糊精用于膜分离, 主要是将固载化 $\beta$-环 糊精共价或非共价地添加到膜材料中, 增强膜的分离性 能，固载化 $\beta$-环糊精在该分离领域的应用相对比较少. 如 Rolling 等 ${ }^{[146]}$ 以 $\alpha, \beta$-环糊精丙烯酸酯和聚乙二醇二甲 基丙烯酸酯为共聚单体, 共聚制成膜材料, 用于石化产 品中芳香族化合物和脂肪族化合物的膜分离. Sanip 等 ${ }^{[147]}$ 通过非共价相互作用, 将 $\beta$-环糊精固载在多层碳 纳米管上, 并将该固载了 $\beta$-环糊精的碳纳米管添加到聚 酰亚胺膜材料中, 用于提高 $\mathrm{CO}_{2}$ 和 $\mathrm{CH}_{4}$ 混合气体中 $\mathrm{CO}_{2}$ 透过的选择性. Ahmad 等 ${ }^{[148]}$ 则通过研磨的方法将 $\beta$-环 糊精固载在多层碳纳米管上, 然后与乙酸纤维素形成混 合矩阵膜, 分离 $\mathrm{CO}_{2}$ 和 $\mathrm{N}_{2}$. $\beta$-环糊精的存在增强了该混 合矩阵膜对 $\mathrm{CO}_{2}$ 和 $\mathrm{N}_{2}$ 的分离性能, 当 $\beta$-环糊精修饰的 多层碳纳米管在混合矩阵膜中的质量含量达到 $0.1 \%$ 时, $\mathrm{CO}_{2}$ 和 $\mathrm{N}_{2}$ 的渗透选择性最佳, $\mathrm{CO}_{2} / \mathrm{N}_{2}$ 达到 40 . 该混合矩 阵膜具有应用于分离空气中有害 $\mathrm{CO}_{2}$ 气体, 降低环境温 室效应的巨大潜力.

由此可见, 固载化 $\beta$-环糊精用于手性分离, 基本集 中在构筑色谱柱手性固定相, 外消旋体的两种构型在 $\beta$ 环糊精单元中进行反复的包结分离, 从而实现两种构型 的基线分离. 而以固载化 $\beta$-环糊精直接进行包结分离, 效果却不是很理想. 至于固载化 $\beta$-环糊精用于膜分离, 目前还基本集中在非手性分离领域. 因此, 今后固载化 $\beta$-环糊精用于手性分离还会继续集中于色谱柱手性固 定相的构筑, 并且 $\beta$-环糊精单元本身的手性本质及多羟 基结构, 易于进一步修饰的特性, 使基于固载化 $\beta$-环糊 精构筑高性能色谱柱手性固定相极具研究价值和应用 前景, 研究前景十分广阔.

\section{5 催化}

尽管 $\beta$-环糊精及其衍生物已广泛应用于催化或促 进有机合成反应, 但固载化 $\beta$-环糊精催化或促进有机合 成反应还十分少见, 并且基本停留在相转移催化或微通 道反应器阶段, 借助 $\beta$-环糊精单元对底物分子的包结络 合作用, 增加底物在水相中的分散, 促进或催化有机合 成反应. 固载的载体有玻璃、树脂、化学合成高分子材 料和天然产物高分子材料. 如 Tahir 等 ${ }^{[149]}$ 以 3-(2,3-环氧
丙氧基)丙基三甲氧基硅烷、乙二胺、5-氯-1-戊炔等为 连接基团，通过 “Click” 反应将 $\beta$-环糊精共价固载在玻 璃微通道反应器内, 形成固载化的相转移催化剂 Immo-CD-55, 以连续流动反应的形式催化芳香叠氮化 物和芳香炔类化合物的 “Click” 环加成反应. 由于 $\beta$ 环糊精优异的相转移催化性能, 几分钟内就可以达到 97\% 99\%的产物收率，并且该固载化的 $\beta$-环糊精相当 稳定，连续使用 $50 \mathrm{~h}$ 而未见催化活性的下降. Kiasat 等 ${ }^{[150]}$ 将 $\beta$-环糊精固载在大孔树脂上(Immo-CD-56), 作 为固一液相转移催化剂, 促进 $\mathrm{NaBH}_{4}$ 水相还原环氧化物 (Eq. 3). 由于 $\beta$-环糊精单元的弱催化和促进作用, 还原 产物收率最高达到了 $90 \%$ 以上, 并且该催化剂可以回收 并重复使用, 重复使用 3 次而未见催化活性的明显降低. Kiasat 等 ${ }^{[151]}$ 又以 Immo-CD-56 为固-液相转移催化剂, 催化苄基卤化物及其衍生物、卤代烷烃和 $\alpha$-溴代苯乙酮 及其衍生物与硫氧酸根、重氮基和乙酸根的亲核取代反 应(Eq. 4), 同样取得了很好的催化效果, 收率最高达到 $93 \%$.
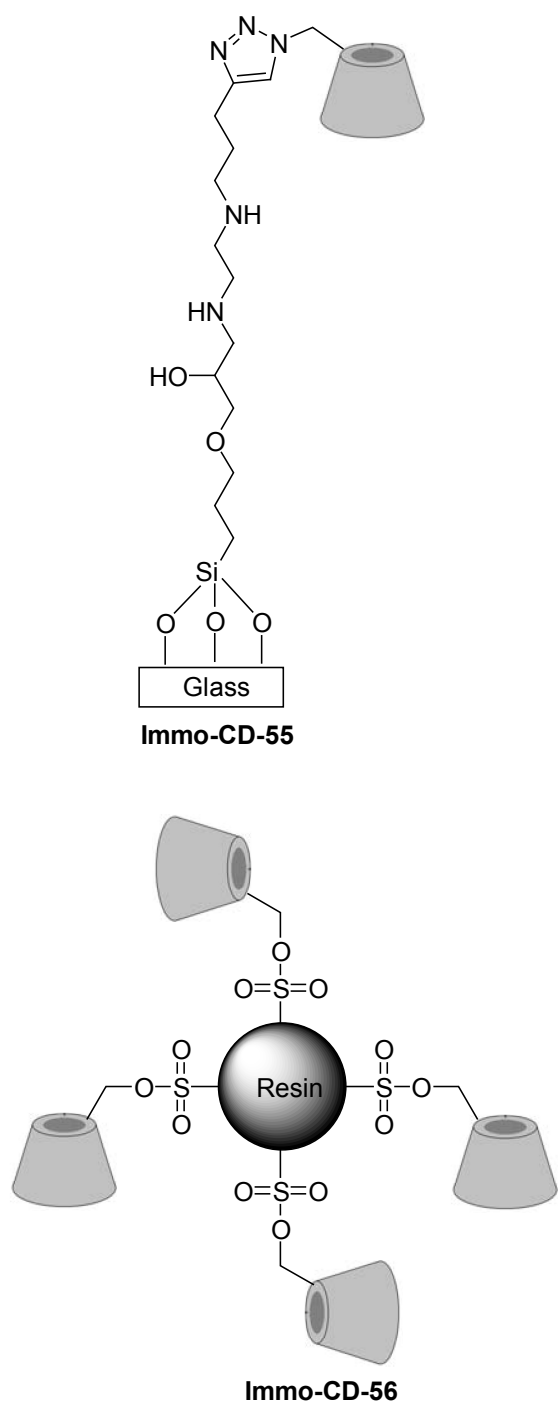

http://sioc-journal. cn/ 


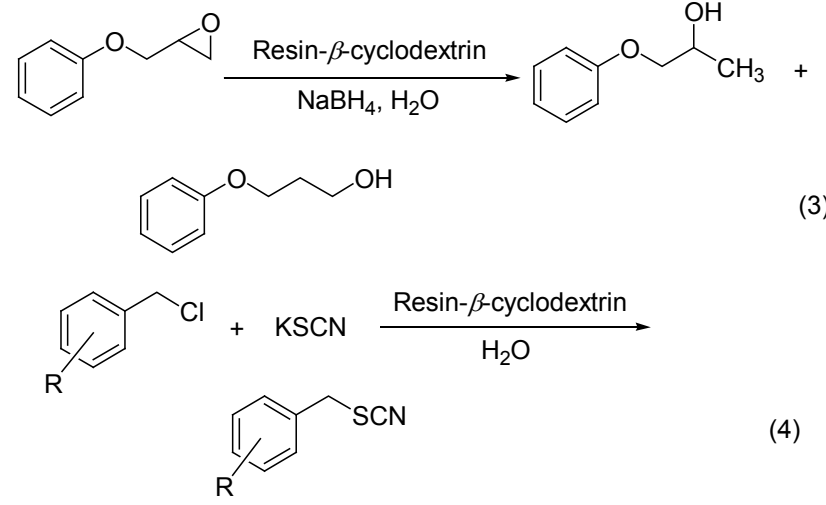

另外, Doyaguez 等 ${ }^{[152]}$ 以含双键的全甲基化 $\beta$-环糊 精衍生物与脯氨酸衍生物为共聚单体, 共聚形成吊坠式 聚合物 Immo-CD-57，以甲基化 $\beta$-环糊精模拟酶的疏水 空腔, 脯氨酸模拟催化活性中心, 构筑 Aldol 催化体系. 以环己酮与 $p$-硝基苯甲醛的水相不对称 Aldol 反应为模 型反应(Eq. 5), ee 最高达到 96\%. 另外, 研究还发现, 该 催化体系的催化性能受到体系 $\mathrm{pH}$ 值的显著影响，当 $\mathrm{pH}$ 为 7.0 时, 该共聚物带负电荷, 呈舒展的直链状态, 可以 快速催化模型反应，但是没有对映选择性; 当 $\mathrm{pH}$ 在脯 氨酸的等电点 3.8 时, 该共聚物呈多链疏水纳米聚集体 状态, 催化模型反应的性能相对较差, 但却表现出优异 的对映选择性. 上述现象也表明在 Aldol 反应中, 催化 活性中心附近具有疏水微环境, 对取得立体选择性具有 重要的促进作用.
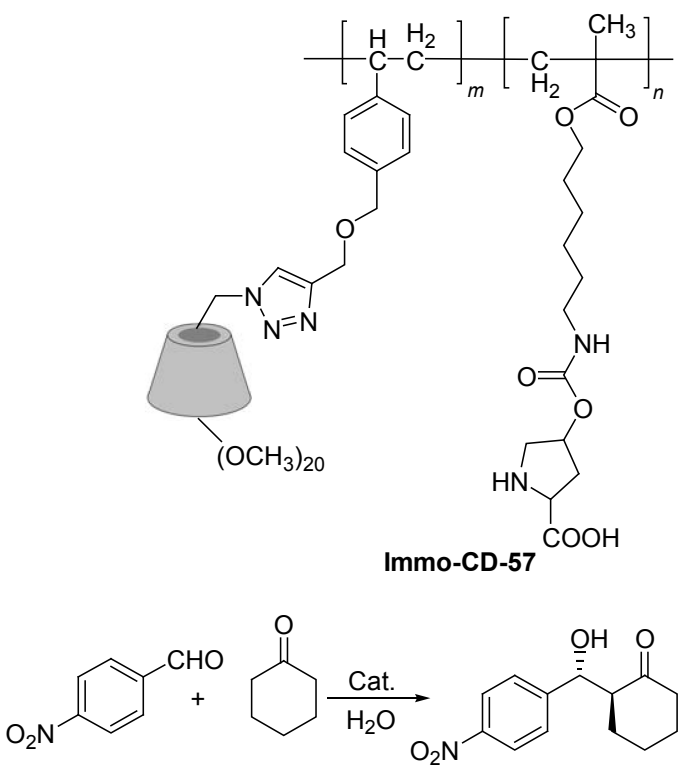

在以天然产物高分子材料为载体固载 $\beta$-环糊精, 催 化或促进有机合成反应方面, Yang 等 ${ }^{[153]}$ 以戊二醛为交 联试剂, 将 $\beta$-环糊精与壳聚糖交联聚合, 实现了 $\beta$-环糊 精在壳聚糖上的固载(Immo-CD-58), 并将该固载化 $\beta$ 环糊精用作非均相相转移催化剂催化水相氧化肉桂醛
制备天然苯甲醛(Eq. 6). 由于 $\beta$-环糊精单元与壳聚糖的 协同促进作用，苯甲醛的收率最高达到了 $78 \%$, 并且该 相转移催化剂可以回收重复使用, 具有广泛用于工业生 产制备天然苯甲醛的潜力. 随后 Yang 等 ${ }^{[154]}$ 又以环氧氯 丙烷为连接基团, 将 $\beta$-环糊精固载在纤维素上 (Immo-CD-59), 催化 $\mathrm{H}_{2} \mathrm{O}_{2}$ 水相氧化肉桂醛生成天然苯 甲醛，同样取得了很好的催化活性和选择性. $60{ }^{\circ} \mathrm{C}$ ，肉 桂醛的转化率达到 $97 \%$, 产物苯甲醛的收率达到 $81 \%$, 并且该相转移催化剂回收重复使用四次而未见催化活 性的明显下降。

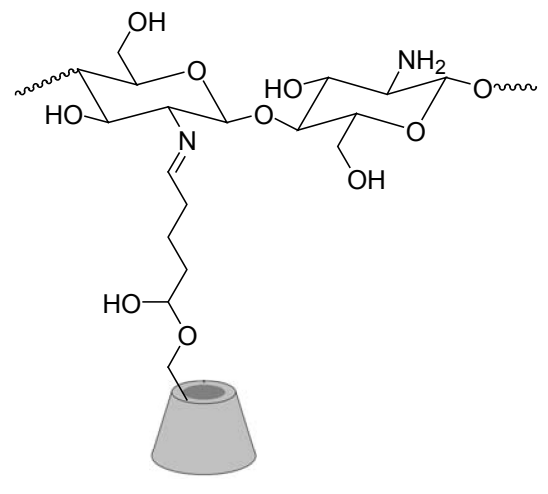

Immo-CD-58
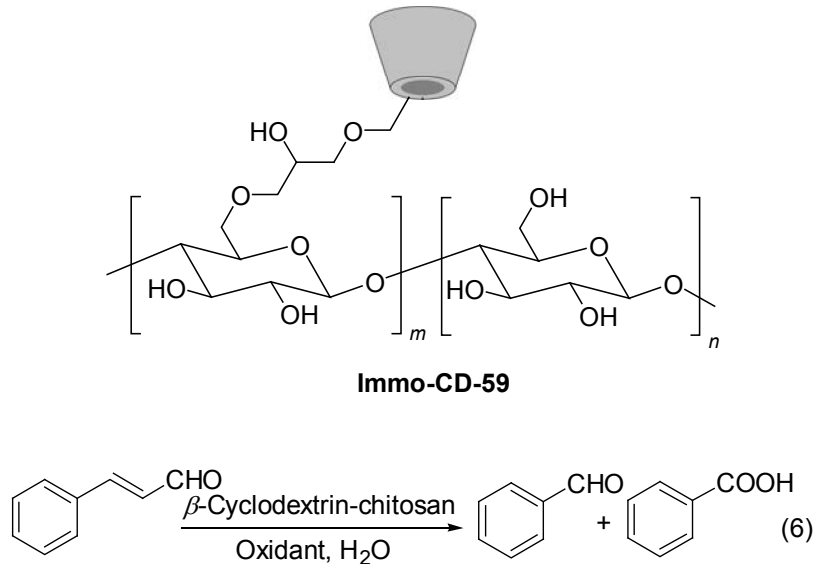

由此可见，固载 $\beta$-环糊精催化或促进有机合成反应 目前还是一个很少有学者涉足的领域，仅有的一些报道 也仅仅是局限在相转移催化或作为非均相的微通道反 应器, 在基于 $\beta$-环糊精已构筑大量超分子仿酶体系并且 成功用于仿生催化一系列有机合成反应的情况下，基于 固载化 $\beta$-环糊精的超分子仿酶体系还未见报道. 基于 $\beta$ 环糊精均相超分子仿酶体系虽具有优异的催化效果，但 却存在回收困难的缺陷，固载化正好可以很好的弥补该 缺陷. 基于 $\beta$-环糊精均相超分子仿酶体系优异的催化性 能及大量文献报道与基于固载化 $\beta$-环糊精超分子仿酶 体系零报道的迥然差别, 使基于固载化 $\beta$-环糊精构筑超 分子仿酶体系十分具有紧迫性，同时又具有可行性. 基 
于 $\beta$-环糊精均相超分子仿酶体系的非均相化, 即基于固 载化 $\beta$-环糊精构筑超分子仿酶体系, 是今后基于 $\beta$-环糊 精构筑超分子仿酶体系的必然归属, 具有极大的研究价 值.

\section{6 织物整理}

固载 $\beta$-环糊精用于织物整理, 主要是将 $\beta$-环糊精固 载在织物纤维上, 借助 $\beta$-环糊精单元的包结络合作用, 将具有杀虫、杀菌、抗菌等生物活性的成分负载在织物 纤维上, 以提高织物的杀虫、杀菌、抗菌等性能. 如 Hebeish 等 ${ }^{[155]}$ 以甲基丙烯酸缩水甘油酯为连接基团, 通 过电子束激发将 $\beta$-环糊精固载在棉纤维上(Immo-CD60), 借助 $\beta$-环糊精单元的包结络合作用负载杀虫剂, 如 氯菊酯和生物烯丙菊酯, 负载了杀虫剂的织物对蚊子具 有很好的驱除、击倒和杀死效果. Bajpai 等 ${ }^{[156]}$ 以柠檬酸 为连接基团, 将 $\beta$-环糊精固载在棉纤维上(Immo-CD61) 负载 $\operatorname{Ag}(\mathrm{I})$, 提高棉纤维的抗菌活性, 由于 $\beta$-环糊精 单元的包结络合作用和连接基团柠檬酸的络合作用, 同 未固载 $\beta$-环糊精单元的棉纤维相比, 显著提高了 $\mathrm{Ag}(\mathrm{I})$ 的缓释效果, 将 $\operatorname{Ag}(\mathrm{I})$ 的释放时间由 $3 \mathrm{~d}$ 提高到 $7 \mathrm{~d}$, 缓释 效果比较明显. Racu 等 ${ }^{[157]}$ 则以一氯均三嗪为连接基团, 将 $\beta$-环糊精固载在大麻纤维上(Immo-CD-62), 借助 $\beta$ -
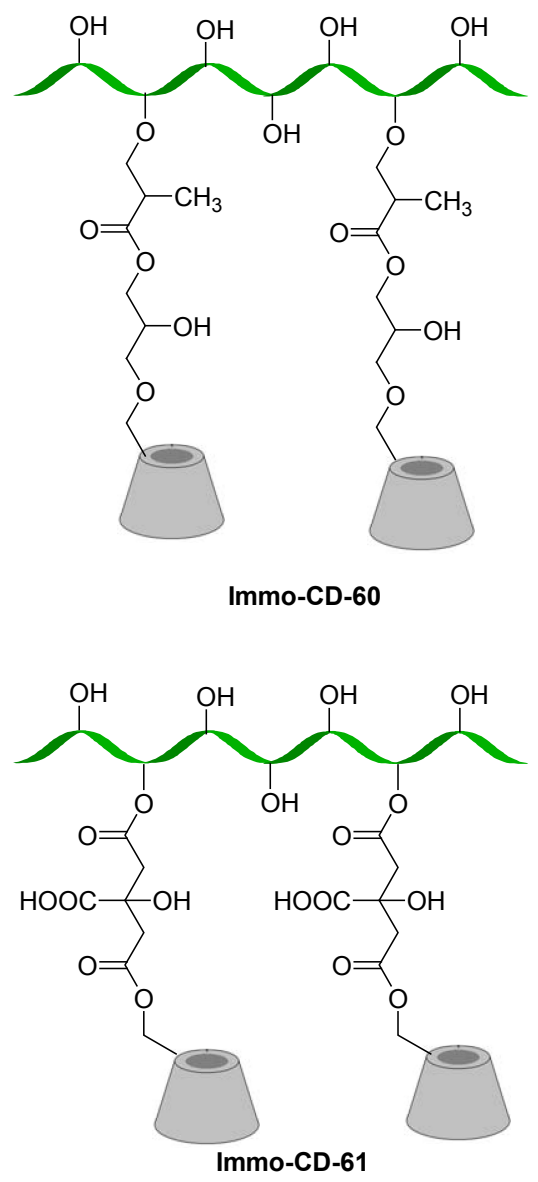

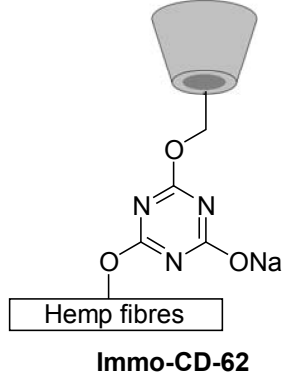

环糊精单元的主-客体包结络合作用将具有抗菌活性的 阿魏酸、咖啡酸、阿魏酸乙酯和尿囊素包结络合在大麻 纤维的表面, 增强大麻纤维的抗菌性能, 取得了很好的 效果.

除了负载杀虫、杀菌、抗菌成分, Nada 等 ${ }^{[158]}$ 分别通 过大气等离子技术和热固载技术将全 $(2,3,6-O$ - 烯丙 基)- $\beta$-环糊精固载在碘氧化纤维素、纤维素过氧化物和 纤维素重氮盐上, 借助 $\beta$-环糊精单元的主-客体包结络 合性能, 将亚油酸、蒈麻油酸和油酸固载在棉纤维上, 制备了固载有伤口愈合剂的棉纤维. 无论是包结了脂肪 酸还是未包结脂肪酸的 $\beta$-环糊精-棉纤维, 均表现出很 好的生物兼容性，是一极具应用前景的伤口包扎材料.

固载 $\beta$-环糊精于织物纤维上进行织物整理, 也是固 载化 $\beta$-环糊精的一个重要应用领域, 但由于本综述的重 点不在于织物整理, 这里只做简要介绍.

\section{7 表面功能化}

固载化 $\beta$-环糊精用于表面功能化, 这里主要是指将 $\beta$-环糊精固载在载体表面上, 借助 $\beta$-环糊精单元的主 客体包结作用, 将功能分子包结固载在载体表面上, 从 而达到表面的功能化, $\beta$-环糊精单元的作用主要是为功 能分子提供一个固载位, 真正发挥功能的主体为 $\beta$-环糊 精固载的客体分子. 如 Zhao 等 ${ }^{[159]}$ 以环氧氯丙烷为连接 基团, 将 $\beta$-环糊精固载在纤维素纤维上(Immo-CD-63), 借助 $\beta$-环糊精单元的主体包结性能与两端具有金刚烷 基团的聚( $\varepsilon$-己内酯)低聚物形成包结络合物, 实现了聚 ( $\varepsilon$-己内酯)低聚物在纤维素纤维表面的固载及纤维素纤 维表面的功能化. 该纤维素纤维表面修饰方法, 可控性 强, 可同时精确地将一种或多种组分固载在纤维素纤维 上，并且固载条件温和，可以有效保持生物活性分子的 活性. Cai 等 ${ }^{[160]}$ 通过 “Click” 反应, 将 $\beta$-环糊精固载在 甲基丙烯酸炔丙酯和臭氧活化的聚偏氟乙烯的共聚物 上, 并以该共聚物制成微孔膜. 借助 $\beta$-环糊精单元的 主-客体包结性能与二金刚烷基聚乙二醇形成包结络合 物, 由于聚乙二醇结构的存在, 该微孔膜在微流状态下, 对蛋白质和污垢具有良好的抵制性. Eker 等 ${ }^{[161]}$ 将 $\beta$-环 糊精固载在微流设备的硅片上，然后借助 $\beta$-环糊精与金 
刚烷基的主-客体相互作用，将带有金刚烷基团的分子 探针固载在硅片上, 于微流设备中构筑化学传感器. 该 传感器可同时检测生理相关的磷酸根离子和炭疽检测 相关的芳香族羒酸. Ji 等 ${ }^{[162]}$ 则通过 “Click” 反应, 将 $\beta$ 环糊精固载在聚已内酰胺(PCL)膜表面上(Immo-CD64), 借助 $\beta$-环糊精的主体包结络合作用包结络合功能 化分子, 改进和提升聚己内酰胺作为人造血管材料的性 能.
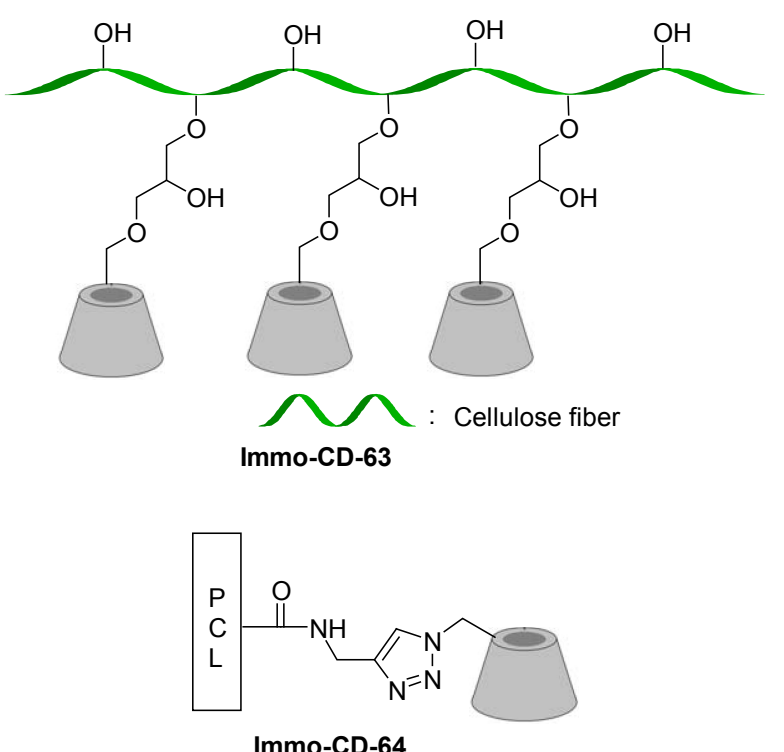

另外, $\mathrm{Li}$ 等 ${ }^{[163]}$ 通过氨基将 $\beta$-环糊精固载在多层碳 纳米管上, 吸附脂肪酶, 达到固载脂肪酶的效果. 将该 固载化的脂肪酶用于催化拆分 $(R, S)$-1-苯基乙醇, 在有 机溶剂正庚烷、离子液体 $[\mathrm{Bmim}] \mathrm{PF}_{6}$ 及二者的混合液中, 固载后的脂肪酶均表现出优异的催化活性, 甚至优于原 始酶的催化活性, 这主要是由于 $\beta$-环糊精可以有效保护 酶的二级结构, 并且固载后酶的分散性提高. 另外, 在 三种反应介质中, 以正庚烷-离子液体 $\left[\mathrm{Bmim}^{-} \mathrm{PF}_{6}\right.$ 混合 液中, 固载的脂肪酶催化效果最佳, 这主要是由于在正 庚烷-离子液体 $[\mathrm{Bmim}] \mathrm{PF}_{6}$ 混合体系中, 催化剂富集于离 子液体相, 底物可以不断地从正庚烷相扩散到离子液体 相进行反应，而产物则由离子液体相不断萃取到正庚烷 相, 底物和产物的不断扩散迁移, 促进催化反应不断进 行.

总之, $\beta$-环糊精单元可以同一系列有机分子形成稳 定的包结络合物, 借助 $\beta$-环糊精单元的主体包结作用, 可以将各种目标功能分子非共价固载在固载有 $\beta$-环糊 精单元的表面上, 并具有相当的固载牢度, 构筑功能化 表面，而且该功能化的表面可以通过客体分子的置换进 行功能的转化, 可控制性及可调节性强. 另外, 功能分 子的固载在室温下, 水相中就可以进行, 不存在剧烈的 化学反应, 可以很好地保持各种生物活性分子的活性,
是一种构筑各种仿生表面和功能化表面的切实可行的 手段，具有极大的研究价值和应用空间.

\section{8 其它应用}

固载化 $\beta$-环糊精除了上述七种比较典型的应用外， 还具有一些其它的应用，如稳定蛋白质二级结构、构筑 智能型水凝胶、稳定金属纳米粒子等，这些应用也具有 比较多的文献报道, 但共性相对较少, 这里只简要介绍 几个代表性的应用. $\mathrm{Li}$ 等 ${ }^{[164]}$ 以 $p$-氨基苯甲酸为连接基 团, 将 $\beta$-环糊精固载在多层碳纳米管上(Immo-CD-65), 用于稳定碳纳米管吸附的牛血清蛋白. $\beta$-环糊精单元的 引入不仅有利于多层碳纳米管在水相中的分散, 促进牛 血清蛋白在多层碳纳米管上的吸附，而且 $\beta$-环糊精还可 以通过与蛋白质残基主-客体相互作用，有利于吸附过 程中蛋白质结构的保持，该结论也从圆二色谱表征中得 到了证实. Maeda 等 ${ }^{[165]}$ 分别借助酰胺基、酯键和醚键将 $\beta$-环糊精固载在聚苯乙炔上, 实现了 $\beta$-环糊精单元在聚 苯乙炔上的固载(Immo-CD-66 Immo-CD-68). 研究发 现, $\beta$-环糊精单元与聚苯乙炔之间的连接基团对该固载 化 $\beta$-环糊精在外部刺激下引起的构型变化具有重要的 影响. 以酰胺基和酯键为连接基团的固载化 $\beta$-环糊精对 1-苯基乙胺 $R / S$ 两种构型表现出对映选择性的凝胶化性 能, 并形成螺旋状的超级结构聚集体. 该研究不仅为其 它的螺旋状超级结构聚集体的构筑提供了理论参考，并 且该聚集体也具有用作智能手性材料的潜力. Schofield 等 ${ }^{[166]}$ 则通过脉冲等离子体沉积技术将 4-乙烯基芐氯沉 积在固体表面上, 然后通过醚化反应将 $\beta$-环糊精固载在 该固体表面上，包结吸附并控制释放香料分子，如薰衣 草、檀香、茉莉香等. 由于 $\beta$-环糊精单元的缓释作用，使 这些香料分子可持续释放近 5 个月，仍能保持中等程度 的香气，并且该固体表面还可以很容易地与香料分子再 包结负载, 恢复如初的芳香. Wang 等 ${ }^{[167]}$ 将 $\beta$-环糊精固 载在纤维素珠上, 作为生物质载体, 通过化学还原将 $\mathrm{Ag}$ 纳米粒子负载在该生物质载体上. $\mathrm{Ag}$ 纳米粒子的负 载, 并不能影响 $\beta$-环糊精的包结性能, 但 $\beta$-环糊精-纤 维素珠生物质载体的存在却大大提高了 $\mathrm{Ag}$ 纳米粒子的 稳定性和抗酸性. 以大肠埃希氏菌和金黄色葡萄球菌为 目标菌种, 研究了 $\mathrm{Ag}$ 纳米粒子的抗菌活性, 最低杀菌 剂量均为 $25 \mathrm{mg}$. 由于该负载 $\mathrm{Ag}$ 纳米粒子的稳定性、抗 酸性及抗菌活性，该 $\beta$-环糊精-纤维素珠- $\mathrm{Ag}$ 可广泛用 于医疗废水的处理.

\section{9 结论与展望}

综上所述，固载化 $\beta$-环糊精的应用已广泛涉足到环 境污染物吸附、药物分子负载和缓释、分析检测、手性 


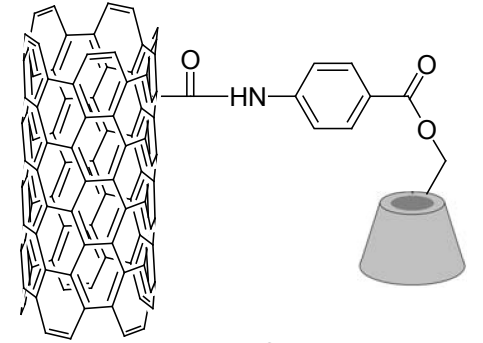

Immo-CD-65

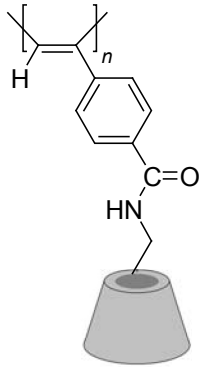

Immo-CD-66
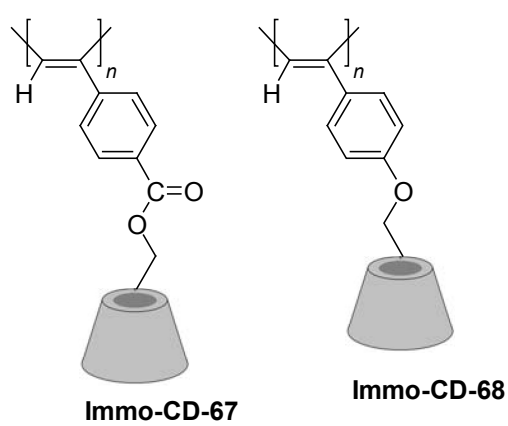

分离、催化、织物整理、表面功能化等领域, 尤其是在 环境污染物吸附、药物分子负载和缓释、分析检测和手 性分离领域, $\beta$-环糊精充分发挥自身包结络合、缓释、 分子识别等性能的同时, 还使载体的综合性能得到显著 提升, 显著提高载体在水相中的分散性、生物兼容性等, 取得了优异的协同效应. 固载化 $\beta$-环糊精在环境污染物 吸附、药物分子负载和缓释、分析检测和手性分离领域 的应用, 已具有相对比较深入的研究, 并取得了优异的 应用效果, 不足之处主要是材料制备过程相对复杂, 成 本高, 不宜大规模制备, 理论研究与实际应用差距较大, 但由于 $\beta$-环糊精单元与生俱来的主体性能、优异的生物 兼容性、可降解性及多羟基易修饰功能化的特性, 使其 在上述领域的应用将继续得到广泛深入的研究, 力求以 简易的制备方法构筑性能更加优异的固载化 $\beta$-环糊精, 并缩小理论研究与实际应用的差距. 这也是固载化 $\beta$-环 糊精在上述四个应用领域今后的前进方向. 同上述四个 应用领域相比, 固载化 $\beta$-环糊精在催化和表面功能化领 域的应用相对偏少, 尤其是在催化有机合成领域, 同 $\beta$ 环糊精及其衍生物、基于 $\beta$-环糊精所构筑的超分子仿酶 体系已广泛应用于催化水相有机合成反应相比 ${ }^{[10,11,13,15,16,37,38,168]}$, 固载化 $\beta$-环糊精在催化有机合成领域的研究还十分少, 并主要停留在简单的相转移催化领域, 基于固载化 $\beta$-环 糊精构筑超分子仿酶体系还未见文献报道. 这也可能与 该类固载化超分子仿酶体系构筑相对较难有关，但基于 $\beta$-环糊精均相超分子仿酶体系的大量文献报道、优异性 能及固载化的优势, 为基于固载化 $\beta$-环糊精超分子仿酶 体系的构筑提供了坚实的基础, 具有极大的参考价值和 研究价值, 研究前景相当迷人. 因此, 本综述借助对固 载化 $\beta$-环糊精及其应用最新研究进展的全面详细介绍,
旨在全面打开基于固载化 $\beta$-环糊精超分子仿酶体系的 构筑研究, 充分发挥 $\beta$-环糊精单元构筑超分子仿酶体系 的天性，同时发挥固载化的优势，克服基于 $\beta$-环糊精均 相超分子仿酶体系回收困难的缺陷, 构筑性能更加优异 的超分子仿酶体系. 至于固载化 $\beta$-环糊精在织物整理和 其它应用领域中的应用, 本质主要是借助 $\beta$-环糊精单元 的主体包结络合作用，同样也受到固载工艺及制备成本 的限制, 只能停留在理论研究阶段, 无法大规模实际应 用. 因此, 开发简易高效的固载工艺并降低固载成本是 今后固载化 $\beta$-环糊精在织物整理和其它应用领域中的 应用的主攻关键技术之一。

\section{References}

[1] Szejtli, J. Chem. Rev. 1998, 98, 1743.

[2] Abdel-Naby, M. A.; El-Refai, H. A.; Abdel-Fattah, A. F. J. Appl. Microbiol. 2011, 111, 1129.

[3] Thombre, R. S.; Kanekar, P. P. J. Microbiol. Biotechnol. Res. 2013, 3,57 .

[4] Flaherty, R. J.; Nshime, B.; DeLaMarre, M.; DeJong, S.; Scott, P.; Lantz, A. W. Chemosphere 2013, 91, 912.

[5] Liu, H. H.; Cai, X. Y.; Chen, J. W. Environ. Sci. Technol. 2013, 47, 5835.

[6] Sanchez-Trujillo, M. A.; Lacorte, S.; Villaverde, J.; Barata, C.; Morillo, E. Environ. Sci. Pollut. Res. 2014, 21, 507.

[7] Kakran, M.; Sahoo, N. G.; Li, L.; Judeh, Z. Chem. Pharm. Bull. 2011, 59, 646

[8] Dong, L. N.; Liu, M.; Chen, A. J.; Wang, Y.; Sun, D. Z. J. Mol. Liq. 2013, 177, 204.

[9] He, J.; Chipot, C.; Shao, X. G.; Cai, W. S. J. Phys. Chem. C 2013, 117, 11750 .

[10] Takahashi, K. Chem. Rev. 1998, 98, 2013.

[11] Ji, H. B.; Huang, L. Q.; Shi, D. P.; Zhou, X. T. Chin. J. Org. Chem. 2008, 28, 2072 (in Chinese). (纪红兵, 黄丽泉, 石东坡, 周贤太, 有机化学, 2008, 28, 2072.)

[12] Bricout, H.; Hapiot, F.; Ponchel, A.; Tilloy, S.; Monflier, E. Curr. Org. Chem. 2010, 14, 1296.

[13] Breslow, R.; Dong, S. D. Chem. Rev. 1998, 98, 1997.

[14] Bjerre, J.; Rousseau, C.; Marinescu, L.; Bols, M. Appl. Microbiol. Biotechnol. 2008, 81, 1.

[15] Marinescu, L.; Bols, M. Curr. Org. Chem. 2010, 14, 1380

[16] Woggon, W. D. Curr. Org. Chem. 2010, 14, 1362.

[17] Dong, Z. Y.; Luo, Q.; Liu, J. Q. Chem. Soc. Rev. 2012, 41, 7890.

[18] Khan, A. R.; Forgo, P.; Stine, K. J.; D'Souza, V. T. Chem. Rev. 1998, 98, 1977.

[19] Engeldinger, E.; Armspach, D.; Matt, D. Chem. Rev. 2003, 103, 4147.

[20] Bellia, F.; La Mendola, D.; Pedone, C.; Rizzarelli, E.; Saviano, M.; Vecchio, G. Chem. Soc. Rev. 2009, 38, 2756.

[21] Martinez, A.; Mellet, C. O.; Fernandez, J. M. G. Chem. Soc. Rev. 2013, 42, 4746 .

[22] Isenbugel, K.; Ritter, H.; Branscheid, R.; Kolb, U. Macromol. Rapid Commun. 2010, 31, 2121.

[23] Nielsen, R.; Nielsen, J. L.; Larsen, K. L. J. Inclusion Phenom. Macrocyclic Chem. 2010, 67, 399.

[24] Isenbugel, K.; Gehrke, Y.; Ritter, H. Macromol. Chem. Phys. 2012, 213, 227.

[25] Sun, T.; Li, J. Y.; Hao, A. Y. Chin. J. Org. Chem. 2012, 32, 2054 
(in Chinese).

(孙涛, 李建业, 郝爱友, 有机化学, 2012, 32, 2054.)

[26] Xu, L. Q.; Yee, Y. K.; Neoh, K. G.; Kang, E. T.; Fu, G. D. Polymer 2013, 54, 2264.

[27] Sun, T.; Zhang, H. C.; Li, Y. M.; Xin, F. F.; Kong, L.; Hao, A. Y. Prog. Chem. 2010, 22, 2156 (in Chinese).

(孙涛, 张华承, 李月明, 辛飞飞, 孙丽, 郝爱友, 化学进展, 2010, 22, 2156.)

[28] Han, C. P.; Li, H. B. Anal. Bioanal. Chem. 2010, 397, 1437.

[29] Yan, J. T.; Li, W.; Liu, K.; Wu, D. L.; Chen, F.; Wu, P. Y.; Zhang, A. Chem. Asian J. 2011, 6, 3260 .

[30] Concheiro, A.; Alvarez-Lorenzo, C. Adv. Drug Delivery Rev. 2013, $65,1188$.

[31] Ohashi, H.; Abe, T.; Tamaki, T.; Yamaguchi, T. Macromolecules 2012, 45, 9742.

[32] Tian, W.; Fan, X. D.; Kong, J.; Liu, Y. Y.; Zhang, W. H. Prog Chem. 2010, 22, 669 (in Chinese).

(田威, 范晓东, 孔杰, 刘郁杨, 张卫红, 化学进展, 2010, 22, 669.)

[33] Sajomsang, W.; Gonil, P.; Ruktanonchai, U. R.; Pimpha, N.; Sramala, I.; Nuchuchua, O.; Saesoo, S.; Chaleawlert-umpon, S.; Puttipipatkhachorn, S. Int. J. Biol. Macromol. 2011, 48, 589.

[34] Chen, Y.; Ye, Y. C.; Li, R. R.; Gao, Y. W.; Tan, H. M. Fibers Polym. 2013, 14, 1058 .

[35] Yang, J. S.; Yang, L. J. Mater. Chem. B 2013, 1, 909.

[36] Chen, Y.; Ye, Y. C.; Wang, L. Y.; Guo, Y. W.; Tan, H. M. J. Appl. Polym. Sci. 2012, 125, E378.

[37] Shen, H. M.; Ji, H. B. Chin. J. Org. Chem. 2011, 31, 791 (in Chinese). (沈海民, 纪红兵, 有机化学, 2011, 31, 791.)

[38] Shen, H. M.; Ji, H. B. Chin. J. Org. Chem. 2012, 32, 975 (in Chinese). (沈海民, 纪红兵, 有机化学, 2012, 32, 975.)

[39] Shen, H. M.; Ji, H. B. Chin. J. Org. Chem. 2012, 32, 1684 (in Chinese). (沈海民, 纪红兵, 有机化学, 2012, 32, 1684.)

[40] Shen, H. M.; Ji, H. B. Carbohydr. Res. 2012, 354, 49

[41] Shen, H. M.; Ji, H. B. Tetrahedron Lett. 2012, 53, 3541.

[42] Shen, H. M.; Ji, H. B. Tetrahedron 2013, 69, 8360.

[43] Shen, H. M.; Wu, H. K.; Ji, H. B.; Shi, H. X. Chin. J. Org. Chem. 2014, 34, 630 (in Chinese). (沈海民，武宏科，纪红兵，史鸿金金，有机化学, 2014, 34, 630.)

[44] Lukhele, L. P.; Krause, R. W. M.; Mamba, B. B.; Momba, M. N. B. Water $\mathrm{Sa}$ 2010, 36, 433 .

[45] Shao, D. D.; Sheng, G. D.; Chen, C. L.; Wang, X. K.; Nagatsu, M. Chemosphere 2010, 79, 679

[46] Bhoi, V. I.; Imae, T.; Ujihara, M.; Murthy, C. N. J. Nanosci. Nanotechnol. 2013, 13, 2604.

[47] Song, X. J.; Yang, F.; Wei, X. W.; Wang, X. B.; She, C. G. Asian J. Chem. 2013, 25, 5762

[48] Chen, P.; Liang, H. W.; Lv, X. H.; Zhu, H. Z.; Yao, H. B.; Yu, S. H. ACS Nano 2011, 5, 5928 .

[49] Roik, N. V.; Belyakova, L. A. J. Colloid Interface Sci. 2011, 362, 172.

[50] Chen, M.; Ding, W. H.; Wang, J.; Diao, G. W. Ind. Eng. Chem. Res. 2013, 52, 2403.

[51] Fuhrer, R.; Herrmann, I. K.; Athanassiou, E. K.; Grass, R. N.; Stark, W. J. Langmuir 2011, 27, 1924.

[52] Pan, J. M.; Zou, X. H.; Wang, X.; Guan, W.; Li, C. X.; Yan, Y. S.; Wu, X. Y. Chem. Eng. J. 2011, 166, 40.

[53] Li, X. H.; Zhao, B. W.; Zhu, K.; Hao, X. K. Chin. J. Chem. Eng. 2011, 19, 938 .
[54] Shen, J. F.; Li, N.; Ye, M. X. J. Alloys Compd. 2013, 580, 239.

[55] Jiang, X.; Qi, Y. J.; Wang, S. G.; Tian, X. Z. J. Hazard. Mater. 2010, 173, 298.

[56] Zou, C. J.; Wu, H. M.; Ma, L.; Lei, Y. J. Appl. Polym. Sci. 2011, 119, 953.

[57] Guo, R.; Wilson, L. D. J. Appl. Polym. Sci. 2012, 125, 1841.

[58] Schofield, W. C. E.; Bain, C. D.; Badyal, J. P. S. Chem. Mater. 2012, 24, 1645.

[59] Teng, M. M.; Li, F. T.; Zhang, B. R.; Taha, A. A. Colloids Surf. A 2011, 385, 229.

[60] Yamada, M.; Hori, M.; Tabuchi, S. Int. J. Biol. Macromol. 2010 47, 201.

[61] Uyar, T.; Havelund, R.; Nur, Y.; Balan, A.; Hacaloglu, J.; Toppare, L.; Besenbacher, F.; Kingshott, P. J. Membr. Sci. 2010, 365, 409.

[62] Lopez-de-Dicastillo, C.; Gallur, M.; Catala, R.; Gavara, R.; Hernandez-Munoz, P. J. Membr. Sci. 2010, 353, 184.

[63] Sharma, A. K.; Mishra, A. K. Int. J. Biol. Macromol. 2010, 47, 410

[64] Chai, K. G.; Ji, H. B. Chem. Eng. J. 2012, 203, 309.

[65] Zhou, Y. M.; Jin, Q. A.; Zhu, T. W.; Akama, Y. F. J. Hazard. Mater. 2011, 187, 303.

[66] Si, H. Y.; Wang, T.; Xu, Z. W. Wood Sci. Technol. 2013, 47, 1177.

[67] Mishra, A. K.; Sharma, A. K. Int. J. Biol. Macromol. 2011, 49, 504.

[68] Qiao, Y. T.; Li, P. L.; Chen, Y. C.; Feng, J.; Wang, J.; Wang, W.; Ma, Y.; Sun, P. C.; Yuan, Z. J. Chromatogr. A 2010, 1217, 7539.

[69] Tahir, M. N.; Kwon, C.; Jeong, D.; Cho, E.; Paik, S. R.; Jung, S. J. Dairy Sci. 2013, 96, 4191.

[70] Tahir, M. N.; Lee, Y. Food Chem. 2013, 139, 475

[71] Wei, G. C.; Dong, R. H.; Wang, D.; Feng, L.; Dong, S. L.; Song, A. X.; Hao, J. C. New J. Chem. 2014, 38, 140.

[72] Anirudhan, T. S.; Sandeep, S.; Divya, P. L. RSC $A d v$. 2012, 2 , 9555.

[73] Hbaieb, S.; Kalfat, R.; Chevalier, Y. Int. J. Pharm. 2012, 439, 234.

[74] Jacobsen, P. A. L.; Nielsen, J. L.; Juhl, M. V.; Theilgaard, N.; Larsen, K. L. J. Inclusion Phenom. Macrocyclic Chem. 2012, 72, 173.

[75] Tang, W. L.; Zhao, J. C.; Sha, B. J.; Liu, H. J. Appl. Polym. Sci. 2013, 127, 2803.

[76] Zhao, M. X.; Li, J. M.; Du, L. Y.; Tan, C. P.; Xia, Q.; Mao, Z. W.; Ji, L. N. Chem. Eur. J. 2011, 17, 5171.

[77] Shi, Y.; Goodisman, J.; Dabrowiak, J. C. Inorg. Chem. 2013, 52, 9418.

[78] Trellenkamp, T.; Ritter, H. Macromolecules 2010, 43, 5538.

[79] Chen, Y.; Zhou, L. Z.; Pang, Y.; Huang, W.; Qiu, F.; Jiang, X. L.; Zhu, X. Y.; Yan, D. Y.; Chen, Q. Bioconjugate Chem. 2011, 22, 1162.

[80] Sun, Z. Y.; Shen, M. X.; Yang, A. W.; Liang, C. Q.; Wang, N.; Cao, G. P. Chem. Commun. 2011, 47, 1072.

[81] Yhaya, F.; Lim, J.; Kim, Y.; Liang, M. T.; Gregory, A. M.; Stenzel, M. H. Macromolecules 2011, 44, 8433.

[82] Bohm, I.; Kreth, S. K.; Ritter, H. Beilstein J. Org. Chem. 2011, 7, 1130.

[83] Kim, C.; Shah, B. P.; Subramaniam, P.; Lee, K. B. Mol. Pharm. 2011, 8, 1955.

[84] Shah, S.; Solanki, A.; Sasmal, P. K.; Lee, K. B. J. Am. Chem. Soc. 2013, 135, 15682.

[85] Yang, X.; Kim, J. C. Int. J. Biol. Macromol. 2011, 48, 661.

[86] Fan, H.; Hu, Q. D.; Xu, F. J.; Liang, W. Q.; Tang, G. P.; Yang, W. T. Biomaterials 2012, 33, 1428.

[87] Zhang, X. J.; Zhang, X. E.; Wu, Z. M.; Gao, X. J.; Shu, S. J.; Wang, Z.; Li, C. X. Carbohydr. Polym. 2011, 84, 1419.

[88] Zhang, X. J.; Zhang, X. G.; Wu, Z. M.; Gao, X. J.; Cheng, C.; Wang, Z.; Li, C. X. Acta Biomater. 2011, 7, 585.

[89] Chaleawlert-Umpon, S.; Nuchuchua, O.; Saesoo, S.; Gonil, P.; 
Ruktanonchai, U. R.; Sajomsang, W.; Pimpha, N. Carbohydr. Polym. 2011, 84, 186.

[90] Sajomsang, W.; Nuchuchua, O.; Gonil, P.; Saesoo, S.; Sramala, I.; Soottitantawat, A.; Puttipipatkhachorn, S.; Ruktanonchai, U. R. Carbohydr. Polym. 2012, 89, 623.

[91] Sajomsang, W.; Nuchuchua, O.; Saesoo, S.; Gonil, P.; Chaleawlert-umpon, S.; Pimpha, N.; Sramala, I.; Soottitantawat, A.; Puttipipatkhachorn, S.; Ruktanonchai, U. R. Carbohydr. Polym. 2013, 92, 321.

[92] Ping, Y.; Liu, C. D.; Zhang, Z. X.; Liu, K. L.; Chen, J. H.; Li, J. Biomaterials 2011, 32, 8328.

[93] Yuan, Z. T.; Ye, Y. J.; Gao, F.; Yuan, H. H.; Lan, M. B.; Lou, K. Y.; Wang, W. Int. J. Pharm. 2013, 446, 191.

[94] Peng, K.; Tomatsu, I.; Korobko, A. V.; Kros, A. Soft Matter 2010, 6,85 .

[95] Li, C.; Luo, G. F.; Wang, H. Y.; Zhang, J.; Gong, Y. H.; Cheng, S. X.; Zhuo, R. X.; Zhang, X. Z. J. Phys. Chem. C 2011, 115, 17651.

[96] Cravotto, G.; Beltramo, L.; Sapino, S.; Binello, A.; Carlotti, M. E. J. Mater. Sci.: Mater. Med. 2011, 22, 2387.

[97] Kang, Y.; Yuan, J. Y.; Yan, Q.; Zheng, L. Y.; Zhou, L. L. Polym. Adv. Technol. 2012, 23, 255.

[98] Yang, Y.; Zhang, Y. M.; Chen, Y.; Chen, J. T.; Liu, Y. J. Med. Chem. 2013, 56, 9725.

[99] Kwon, C.; Kang, Y. J.; Jeon, S.; Jung, S.; Hong, S. Y.; Kang, S. Macromol. Biosci. 2012, 12, 1452.

[100] Chen, L. M.; Zhao, X.; Lin, Y.; Huang, Y. B.; Wang, Q. Chem. Commun. 2013, 49, 9678.

[101] Kim, H.; Kim, S.; Park, C.; Lee, H.; Park, H. J.; Kim, C. Adv. Mater. 2010, 22, 4280.

[102] Mei, X.; Yang, S.; Chen, D. Y.; Li, N. J.; Li, H.; Xu, Q. F.; Ge, J. F.; Lu, J. M. Chem. Commun. 2012, 48, 10010.

[103] Wang, C.; Li, Z. X.; Cao, D.; Zhao, Y. L.; Gaines, J. W.; Bozdemir, O. A.; Ambrogio, M. W.; Frasconi, M.; Botros, Y. Y.; Zink, J. I.; Stoddart, J. F. Angew. Chem., Int. Ed. 2012, 51, 5460.

[104] Nadrah, P.; Maver, U.; Jemec, A.; Tisler, T.; Bele, M.; Drazic, G.; Bencina, M.; Pintar, A.; Planinsek, O.; Gaberscek, M. ACS Appl. Mater. Interfaces 2013, 5, 3908.

[105] Huang, J.; Feng, Z. Y.; Yang, L. M.; Qian, Y.; Zhang, Q. X.; Li, F. Anal. Methods-UK 2012, 4, 4264.

[106] Yu, Y.; Chen, X.; Wei, Y.; Liu, J. H.; Huang, X. J. Anal. Chem. 2012, 84, 9818 .

[107] Diez, P.; Piuleac, C. G.; Martinez-Ruiz, P.; Romano, S.; Gamella, M.; Villalonga, R.; Pingarron, J. M. Anal. Bioanal. Chem. 2013, $405,3773$.

[108] Wang, J.; Kong, L. T.; Guo, Z.; Xu, J. Y.; Liu, J. H. J. Mater. Chem. 2010, 20, 5271

[109] Xie, Y. F.; Wang, X.; Han, X. X.; Xue, X. X.; Ji, W.; Qi, Z. H.; Liu, J. Q.; Zhao, B.; Ozaki, Y. Analyst 2010, 135, 1389.

[110] Chen, X.; Cheng, X. Y.; Gooding, J. J. Anal. Chem. 2012, 84, 8557.

[111] Zhang, Z. X.; Wang, J. A.; Wang, X. L.; Wang, Y.; Yang, X. R. Talanta 2010, 82,483 .

[112] Xu, C. H.; Wang, J. C.; Wan, L.; Lin, J. J.; Wang, X. B. J. Mater. Chem. 2011, 21, 10463.

[113] Mondal, A.; Jana, N. R. Chem. Commun. 2012, 48, 7316.

[114] Guo, Y. J.; Guo, S. J.; Li, J.; Wang, E. K.; Dong, S. J. Talanta 2011, 84,60 .

[115] Liu, J. L.; Chen, Y. H.; Guo, Y. J.; Yang, F. L.; Cheng, F. Q. J. Nanomater. 2013, 632809.

[116] Kong, L. T.; Wang, J.; Meng, F. L.; Chen, X.; Jin, Z.; Li, M. Q.; Liu, J. H.; Huang, X. J. J. Mater. Chem. 2011, 21, 11109.

[117] Yang, L. Z.; Xu, Y.; Wang, X. H.; Zhu, J.; Zhang, R. Y.; He, P. G.; Fang, Y. Z. Anal. Chim. Acta 2011, 689, 39.
[118] Hu, Y. F.; Zhang, Z. H.; Zhang, H. B.; Luo, L. J.; Zhang, M. L.; Yang, X.; Yao, S. Z. Chin. J. Chem. 2012, 30, 377.

[119] Villalonga, R.; Diez, P.; Gamella, M.; Reviejo, J.; Pingarron, J. M. Electroanalysis 2011, 23, 1790 .

[120] Rather, J. A.; Debnath, P.; De Wael, K. Electroanalysis 2013, 25, 2145.

[121] Shang, Z. B.; Hu, S.; Wang, Y.; Jin, W. J. Luminescence 2011, 26, 585.

[122] Chen, X. F.; Zhou, M.; Chang, Y. P.; Ren, C. L.; Chen, H. L.; Chen, X. G. Appl. Surf. Sci. 2012, 263, 491.

[123] Cao, Y. J.; Wu, S. S.; Liang, Y. Z.; Yu, Y. J. Mol. Struct. 2013, $1031,9$.

[124] Xu, X. M.; Liu, Z.; Zhang, X.; Duan, S.; Xu, S.; Zhou, C. L. Electrochim. Acta 2011, 58, 142.

[125] Han, C. P.; Hou, X.; Zhang, H. C.; Guo, W.; Li, H. B.; Jiang, L. J. Am. Chem. Soc. 2011, 133, 7644.

[126] Zhang, F. F.; Gu, S. Q.; Ding, Y. P.; Zhang, Z.; Li, L. Anal. Chim. Acta 2013, 770, 53.

[127] Maffeo, D.; Velkov, Z.; Misiakos, K.; Mergia, K.; Paulidou, A.; Zavali, M.; Mavridis, I. M.; Yannakopoulou, K. J. Colloid Interface Sci. 2011, 358, 369.

[128] Liu, X. Y.; Fang, H. X.; Yu, L. P. Talanta 2013, 116, 283.

[129] Ai, F.; Li, L. S.; Ng, S. C.; Tan, T. T. Y. J. Chromatogr. A 2010, 1217, 7502.

[130] Li, L. S.; Wang, Y.; Young, D. J.; Ng, S. C.; Tan, T. T. Y. Electrophoresis 2010, 31, 378.

[131] Chelvi, S. K. T.; Yong, E. L.; Gong, Y. H. J. Sep. Sci. 2010, 33, 74.

[132] Wang, Y.; Young, D. J.; Tan, T. T. Y.; Ng, S. C. J. Chromatogr. A 2010, 1217, 5103.

[133] Yuan, R. J.; Wang, Y.; Ding, G. S. Anal. Sci. 2010, 26, 943.

[134] Zhao, J.; Tan, D.; Chelvi, S. K. T.; Yong, E. L.; Lee, H. K.; Gong, Y. H. Talanta 2010, 83, 286.

[135] Li, X.; Zhou, Z. M.; Dai, L.; Zhou, W. H.; Wang, J. L. Talanta 2011, 86, 452 .

[136] Li, X.; Zhou, Z. M.; Zhou, W. H.; Dai, L.; Li, Z. H. Analyst 2011, 136, 5017.

[137] Wang, H. S.; Jiang, P.; Zhang, M.; Dong, X. C. J. Chromatogr. A 2011, 1218,1310

[138] Zhang, Z. B.; Wu, M. H.; Wu, R. A.; Done, J.; Ou, J. J.; Zou, H. F. Anal. Chem. 2011, 83, 3616.

[139] Wang, R. Q.; Ong, T. T.; Ng, S. C. Tetrahedron Lett. 2012, 53, 2312.

[140] Ai, F.; Wang, Y.; Chen, H.; Yang, Y. H.; Tan, T. T. Y.; Ng, S. C. Analyst 2013, 138, 2289.

[141] Lv, Y. Q.; Mei, D. P.; Pan, X. X.; Tan, T. W. J. Chromatogr. B 2010, 878, 2461.

[142] Li, M.; Liu, X.; Jiang, F. Y.; Guo, L. P.; Yang, L. J. Chromatogr. A 2011, $1218,3725$.

[143] He, K. C.; Qiu, F. X.; Qin, J.; Yan, J.; Yang, D. Y. Korean J. Chem. Eng. 2013, 30, 2078.

[144] Zhu, W. X.; Wang, Q. Y.; Du, K. F.; Yao, S.; Song, H. Chin. Sci. Bull. 2013, 58, 3390.

[145] Lai, S. M.; Gu, J. Y.; Huang, B. H.; Chang, C. M. J.; Lee, W. L. J. Chromatogr. B 2012, 887, 112.

[146] Rolling, P.; Lamers, M.; Staudt, C. J. Membr. Sci. 2010, 362, 154.

[147] Sanip, S. M.; Ismail, A. F.; Goh, P. S.; Ng, B. C.; Abdullah, M. S.; Soga, T.; Tanemura, M.; Yasuhiko, H. Nano 2010, 5, 195.

[148] Ahmad, A. L.; Jawad, Z. A.; Low, S. C.; Zein, S. H. S. J. Membr. Sci. 2014, 451, 55.

[149] Tahir, M. N.; Qamar, R. U.; Adnan, A.; Cho, E.; Jung, S. Tetrahedron Lett. 2013, 54, 3268.

[150] Kiasat, A. R.; Sayyahi, S. Catal. Commun. 2010, 11, 484. 
[151] Kiasat, A. R.; Zarinderakht, N.; Sayyahi, S. Chin. J. Chem. 2012, 30,699 .

[152] Doyaguez, E. G.; Rodriguez-Hernandez, J.; Corrales, G.; Fernandez-Mayoralas, A.; Gallardo, A. Macromolecules 2012, 45, 7676.

[153] Yang, Z. J.; Zeng, H.; Zhou, X. T.; Ji, H. B. Supramol. Chem. 2013, $25,233$.

[154] Yang, Z. J.; Ji, H. B. ACS Sustainable Chem. Eng. 2013, 1, 1172.

[155] Hebeish, A.; El-Sawy, S. M.; Ragaei, M.; Hamdy, I. A.; El-Bisi, M. K.; Abdel-Mohdy, F. A. Carbohydr. Polym. 2014, 99, 208.

[156] Bajpai, M.; Gupta, P.; Bajpai, S. K. Fibers Polym. 2010, 11, 8.

[157] Racu, C.; Cogeanu, A. M.; Diaconescu, R. M.; Grigoriu, A. Text. Res. J. 2012, 82, 1317.

[158] Nada, A. A.; Hauser, P.; Hudson, S. M. Plasma Chem. Plasma Process 2011, 31, 605.

[159] Zhao, Q.; Wang, S. F.; Cheng, X. J.; Yam, R. C. M.; Kong, D. L.; Li, R. K. Y. Biomacromolecules 2010, 11, 1364.
[160] Cai, T.; Neoh, K. G.; Kang, E. T. Macromolecules 2011, 44, 4258

[161] Eker, B.; Yilmaz, M. D.; Schlautmann, S.; Gardeniers, J. G. E.; Huskens, J. Int. J. Mol. Sci. 2011, 12, 7335.

[162] Ji, Q.; Zhang, S.; Zhang, J. M.; Wang, Z. H.; Wang, J. N.; Cui, Y.; Pang, L. Y.; Wang, S. F.; Kong, D. L.; Zhao, Q. Biomacromolecules 2013, 14, 4099.

[163] Li, L. L.; Feng, W.; Pan, K. H. Colloids Surf., B 2013, 102, 124.

[164] Li, L. L.; Feng, W.; Ji, P. J. AIChE J. 2011, 57, 3507.

[165] Maeda, K.; Mochizuki, H.; Osato, K.; Yashima, E. Macromolecules 2011, 44, 3217.

[166] Schofield, W. C. E.; Badyal, J. P. S. ACS Appl. Mater. Inter. 2011, 3, 2051.

[167] Wang, T.; Li, B.; Lin, L. Appl. Biochem. Biotechnol. 2013, 169, 1811.

[168] Rao, K. R.; Nageswar, Y. V. D.; Sridhar, R.; Reddy, V. P. Curr. Org. Chem. 2010, 14, 1308. 